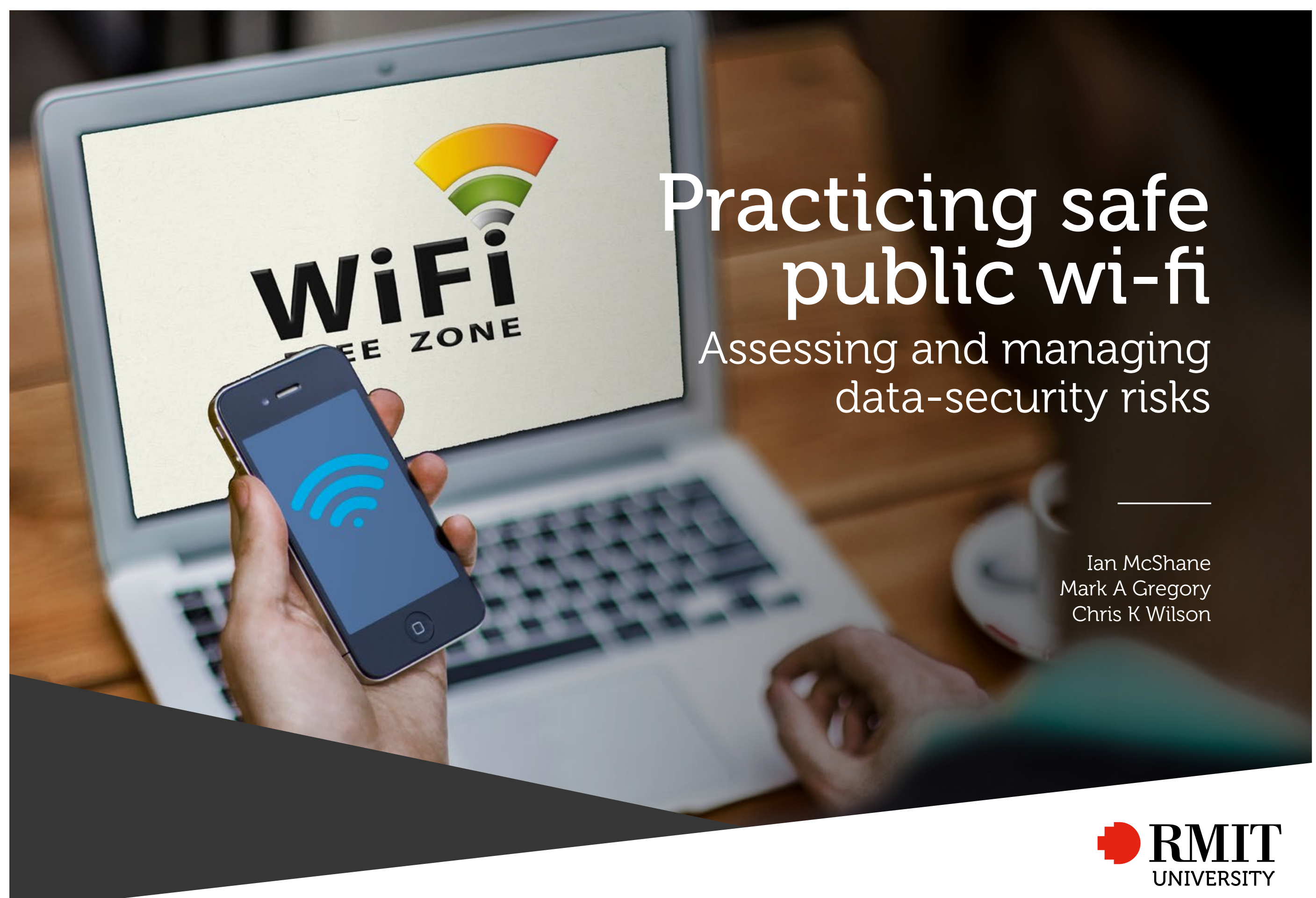


Practicing safe public wi-fi

Assessing and managing data-security risks

December 2016

Authored by: Ian McShane, Mark A Gregory \& Chris K Wilson

Published by:

Centre for Urban Research (CUR)

RMIT University | City campus

Building 15, Level 4

124 La Trobe Street

Melbourne VIC 3000

www.cur.org.au

@RMIT_CUR

facebook.com/rmitcur

Layout and design:

Chanel Bearder

ISBN: 978-0-9941890-9-7

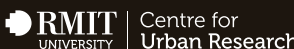




\section{Practicing safe public wi-fi Assessing and managing data-security risks}

Ian McShane, Mark A Gregory \& Chris K Wilson

About the Authors

Dr Ian McShane

lan is the Deputy Director and Senior Research Fellow at RMIT University's Centre for Urban Research

His research focuses on culture, education and urban infrastructure.

Dr Mark A Gregory

Mark is a Senior Lecturer in the School of Engineering. He is the Managing Editor of the Australian Journal of Telecommunications and the Digital Economy and has more than 100 publications including his book, journal and conference papers covering topics in the areas of cyber-security, fibre and

wireless networks, public policy and technical risk.

\section{Dr Chris K Wilson}

Chris is a Research Fellow with the RMIT Centre for Urban Research. His expertise is in examining the historical and contemporary nature of communication infrastructure provision, its underlying

social, technological, economic and governmental determinants, and downstream impact on cultural production and innovation 


\section{Contents}

Executive Summary

Introduction

Public wi-fi regulation, risks and security

Defining public wi-fi

How is public wi-fi regulated?

Public wi-fi insecurities

What do we know about risk perceptions and behaviours?

Public wi-fi network terms and conditions: serving whose interests?

Have government authorities alerted public wi-fi users of security issues?

What can consumers do to enhance their security when using public wi-fi? 
Wi-fi at home

Public wi-fi access

Public wi-fi access: Device types

Activities conducted on public wi-fi networks

Wi-fi or Mobile data?

Public wi-fi security

Public wi-fi protection tools - Awareness 
1. Executive Summary
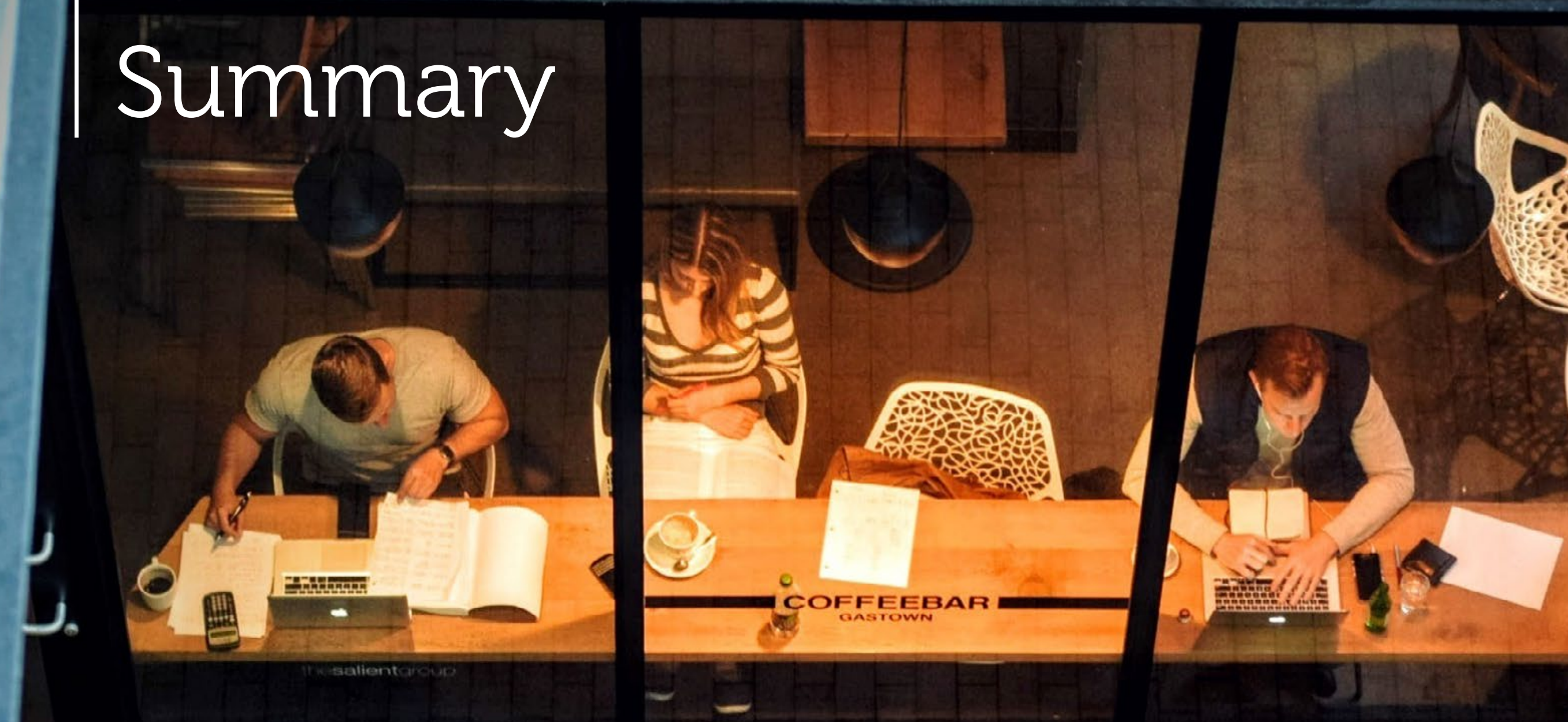

回 
Public wi-fi is becoming a key part of Australia's communication system. However, the convenience and accessibility that make public wi-fi so popular also make it vulnerable to malevolent or illegal activities, particularly targeted at intercepting sensitive or valuable personal information.

Despite its popularity, we know little about how consumers use public wi-fi, their understanding of the technology, and their expectations of service providers. This study contributes to filling knowledge gaps in this field.

The study analyses data from the first large scale Australian survey of public wi-fi use. The survey, designed by RMIT University and Di Marzio Research and administered by Di Marzio Research in 2014, gathered data from a nationally representative sample of 1,200 respondents on mobile broadband use and compared activities on more secure mobile $3 G$ and $4 G$ networks, with activities on public wi-fi networks. The survey gathered data on user awareness of public wi-fi network security issues, and how this awareness influenced decision-making on network use.

The survey data is introduced and contextualised by a discussion of public wi-fi regulation, risk and security issues. Analysis of the survey data is also contextualised with findings from fieldwork on public wi-fi provision undertaken by the RMIT project team in several Australian states. The discussion concludes with suggestions on simple actions network users can take to secure their communications.

In addition to providing baseline data at a time when investment in public wi-fi is surging in Australia, the study is intended to inform awareness campaigns on the safe use of public wi-fi networks. 

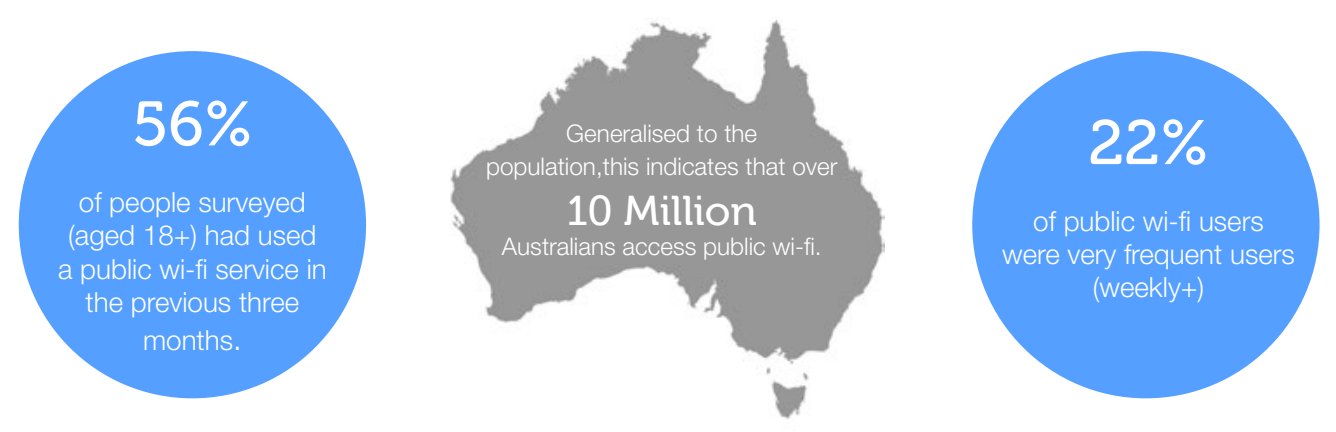

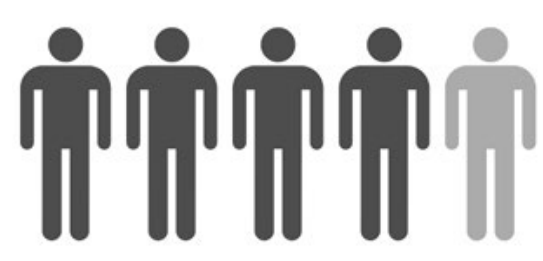

Four in five people aged $18-24$ years had accessed public wi-fi in the previous three months
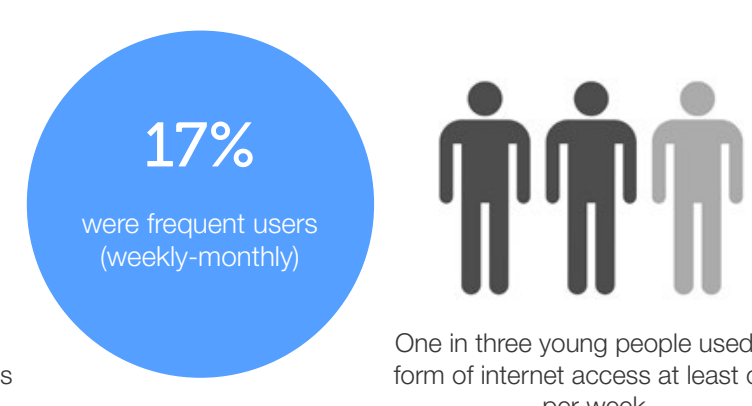

One in three young people used this form of internet access at least once per week.

Public wi-fi networks provided by businesses are the most well-utilised network type.

The most used public wi-fi networks were provided by cafes and restaurants, with shopping centres and

hotel/motel accommodation providers also well

utilised. Networks in public spaces, such as parks or city

squares, were accessed in the previous three months by

respondents. This was a similar rate of access to that of Telstra's new wi-fi service Telstra Air.
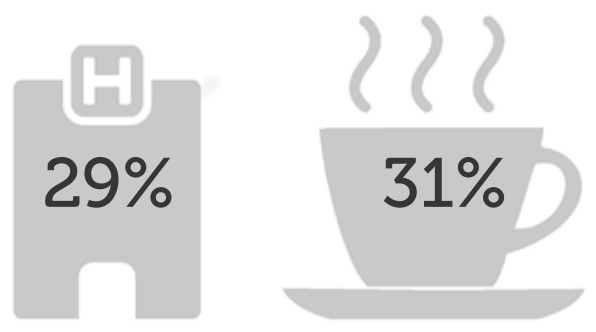

$58 \%$

$16 \%$

Public wi-fi is frequently used for work-related purposes

Public wi-fi is especially significant for the young and the elderly

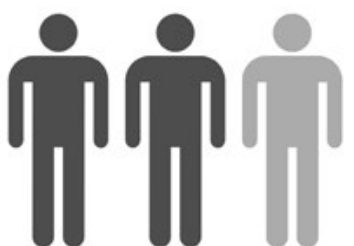

Approximately one in three younger subscribers had access to less than $1 \mathrm{~GB}$ of mobile data per month
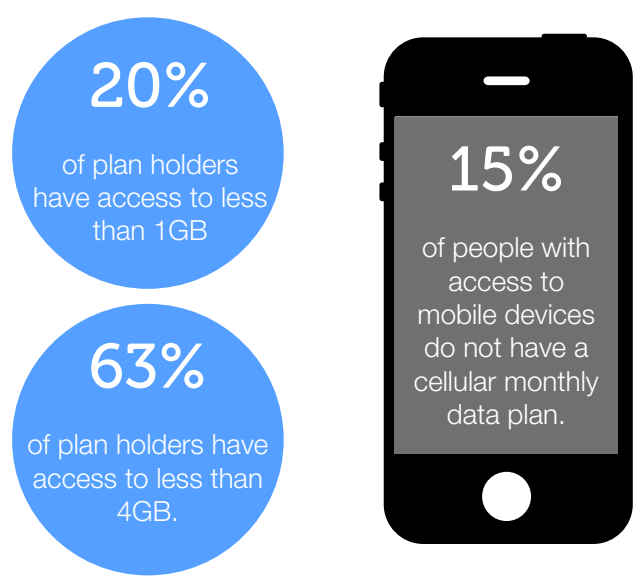
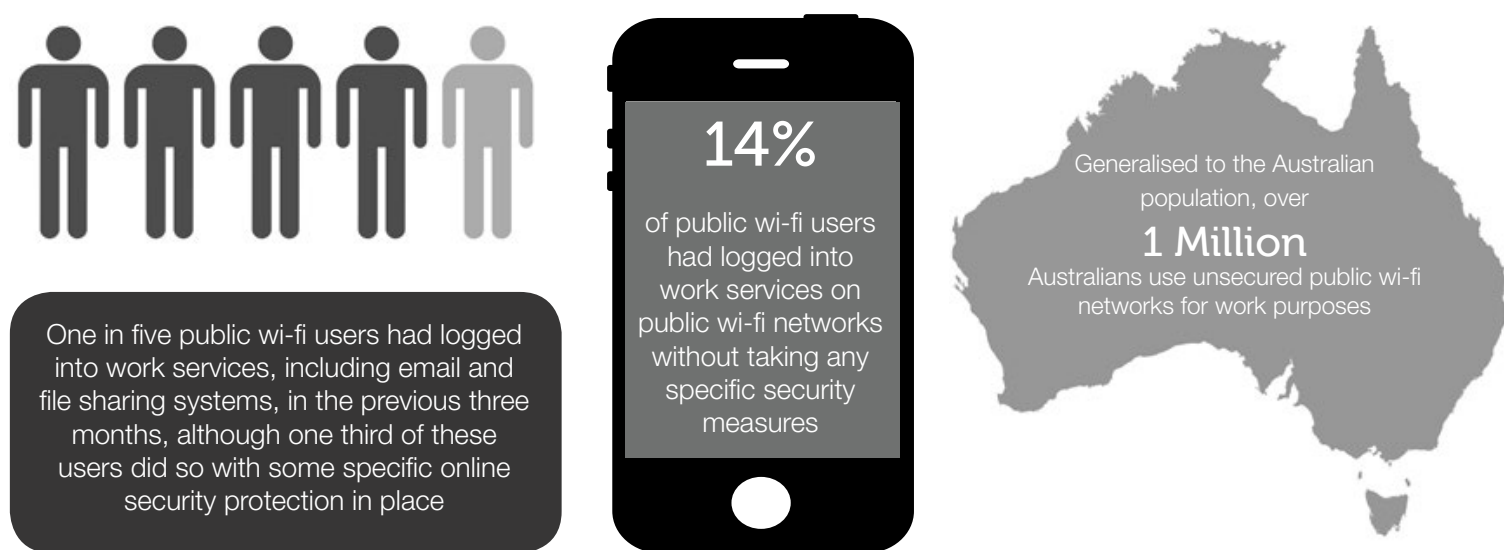

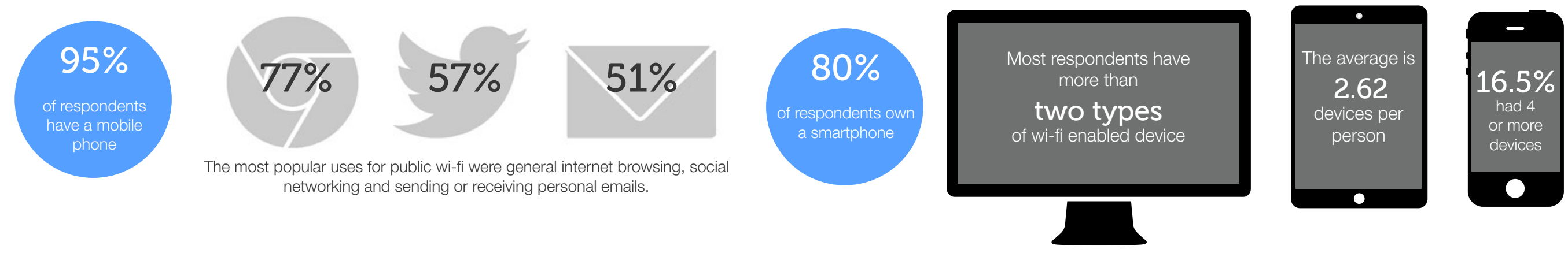

Awareness of public wi-fi security issues does not necessarily change behaviour

- $60 \%$ of public wi-fi users recognised that public wi-fi networks were somewhat insecure. Those who had conducted financial transactions on public wi-fi networks were more likely to perceive these networks as fairly or very secure.

- Almost half of the public wi-fi users who conducted financial transactions recognised the networks were insecure, but proceeded anyway, preferring convenience over security.

- When public wi-fi and cellular networks are available, almost one in five of public wi-fi users always choose to connect using wi-fi.

- $\quad 19 \%$ of survey respondents indicated they had chosen not to use some networks because of security concerns. More commonly, though, concerns over privacy, log-in problems and quality of service were cited as reasons for not accessing public wi-fi.

- $\quad 83 \%$ of public wi-fi users considered that authenticating with a password was important or very for protecting personal information.

The terms and conditions governing public wi-fi network use do not consistently outline user risks

- Most public wi-fi networks are governed by non-negotiable terms and conditions (T\&Cs). While there are examples of concise, plain language T\&Cs, many are long and legalistic, and difficult to access on a mobile screen. Security advice and alerts are often buried at the end of T\&Cs.
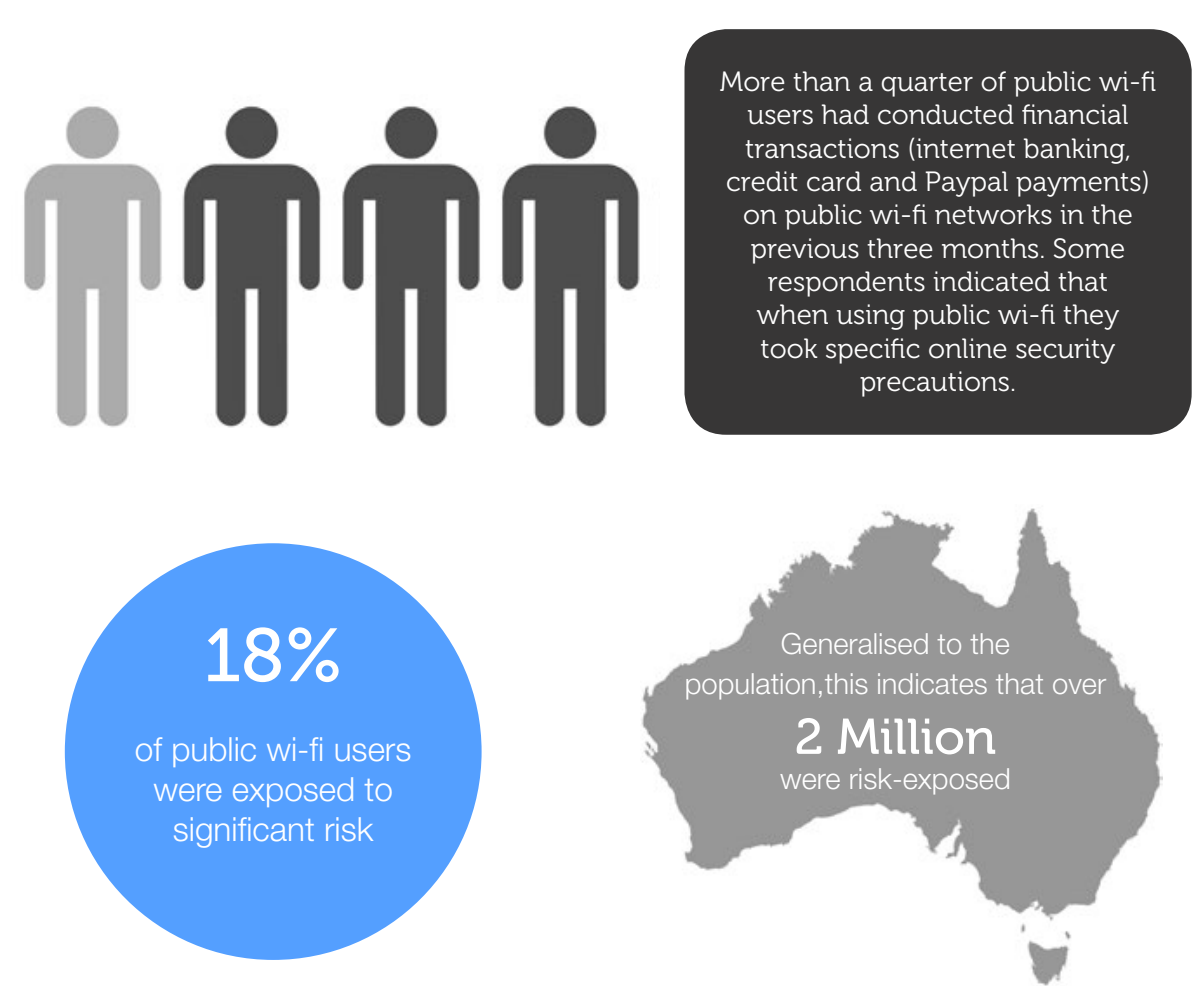
The report highlights shared challenges for public wi-fi users, employers, public wi-fi network providers, and policy-makers to promote public wi-fi security, while retaining the benefits of accessibility offered by this communication technology.

\section{In particular:}

- $\quad$ there is a need for greater awareness of the risks of using public wi-fi and the security measures users can implement to minimise these risks. Public wi-fi security can be boosted with some simple steps, such as using a Virtual Private Network [VPN] or DNS Proxy, and/or ensuring that sites and services that are used operate under HTTPS or SSL protocols.

- our survey data on work-related use of public wi-fi, in line with wider trends in mobile work and bring-your-own-device (BYOD) arrangements, suggest that businesses and employers, and their representative bodies, should be active in developing protocols and procedures relating to public wi-fi use. Given the level of financial transactions conducted over insecure public networks, as shown in the data, financial institutions have a strong incentive to participate in publicity campaigns.

- $\quad$ public wi-fi network providers should assist in promoting security awareness at user log-in stage. Terms and conditions should prioritise security information and follow best practice in network set up and operation. Network providers should check access points regularly to ensure network integrity.

- the limited security awareness of public wi-fi users, as evidenced by the survey data, reinforces earlier survey data obtained by the Commonwealth Department of Communications and the Arts showing limited awareness of information sources for online security information. This suggests that more vigorous and perhaps targeted publicity is required. However, the prevailing emphasis on cybersafety, particularly aimed at children, needs to be supplemented with a more expansive concept of cybersecurity.

\section{DRMIT $\mid \begin{aligned} & \text { Centre for } \\ & \text { UNversir }\end{aligned}$ Urban Research}




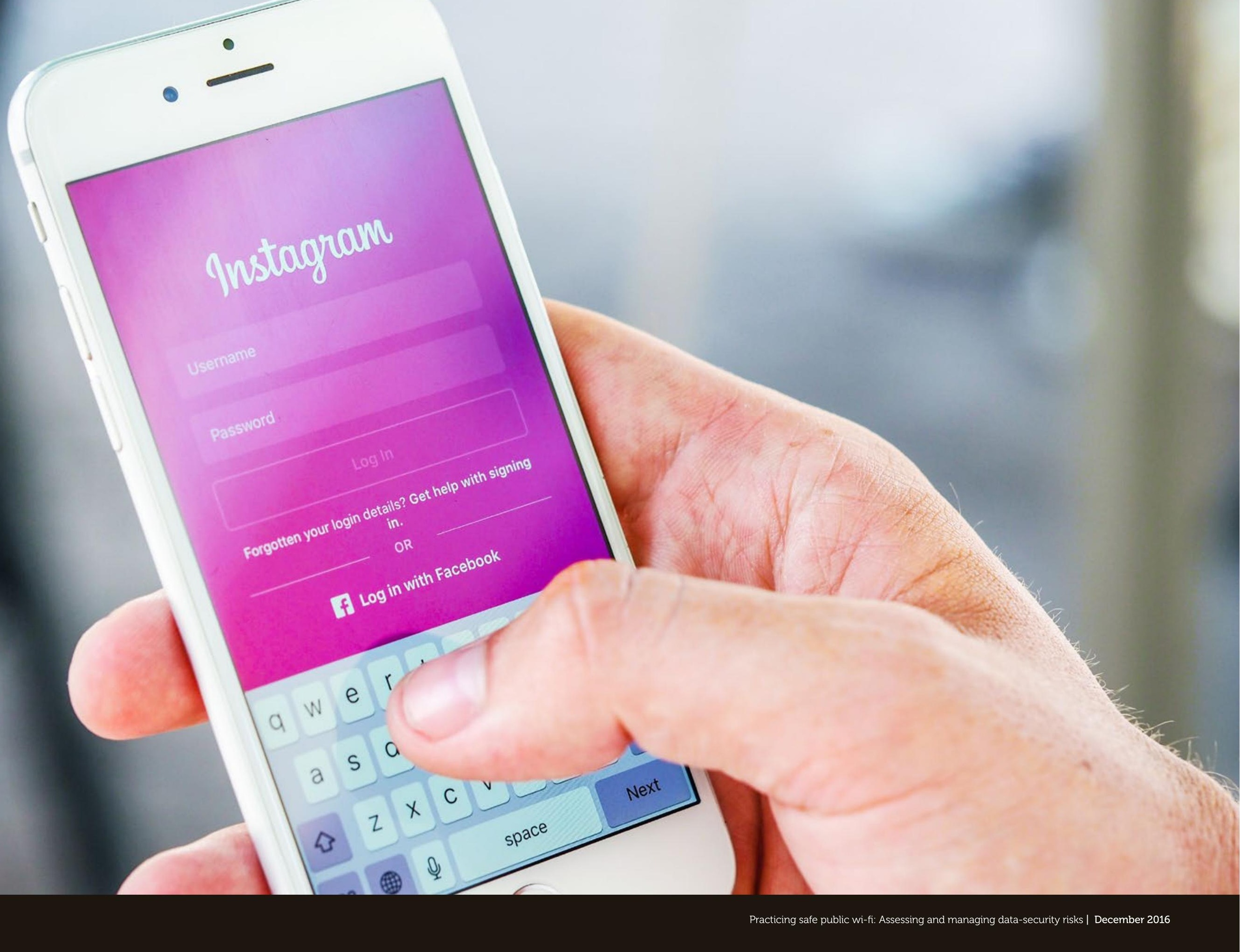


2. In roduction

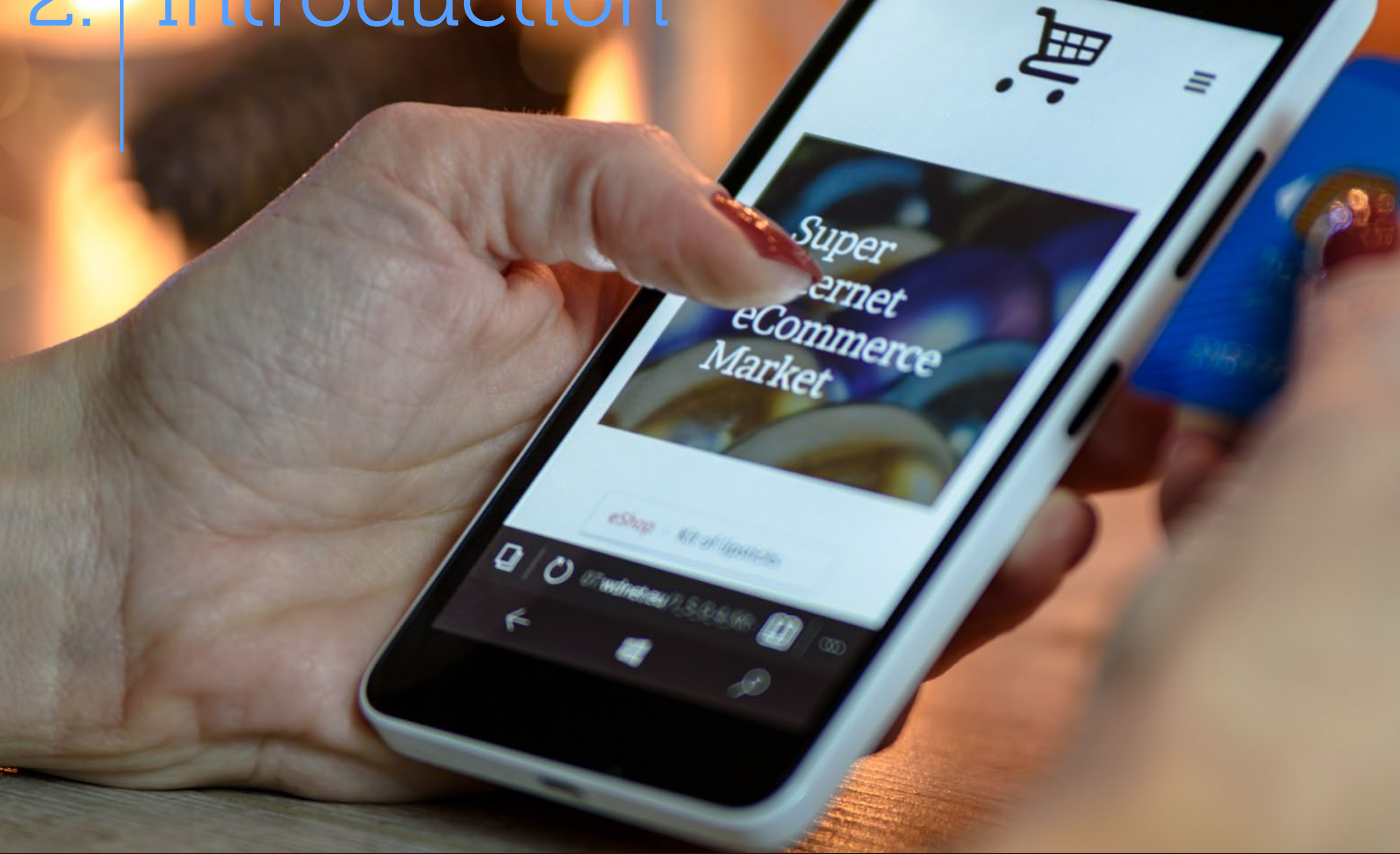


Public wi-fi ${ }^{1}$ is becoming a key part of Australia's communications system. While the provision of wi-fi networks in public and publicly accessible spaces has long been a feature of cities elsewhere in the world, there has been a recent surge of investment in public wi-fi in Australia.

This includes investment by Australian state and municipal governments, some community organisations, and an array of commercial enterprises that include small and large retail and service businesses (from cafes to department stores) and commercial space operators (such as shopping centre owners and airport authorities). There has been a corresponding increase in public wi-fi use. A recent Australian Communications and Media Authority (ACMA) report identified a $21 \%$ year-on-year increase in the number of Australians using this technology to access the internet and a six-fold increase over the previous five years. ${ }^{2}$

The proliferation of public networks has been encouraged by light regulation and the availability of off-the-shelf plug-and-play wi-fi hardware requiring minimum technical knowledge and financial outlay. Public use has been encouraged by limiting connectivity barriers, often through the provision of open networks that do not require a password or common-password networks where all users share the same password to connect. The characteristic accessibility of public wi-fi is, however, its greatest vulnerability.

While data that is transmitted wirelessly can be examined by third parties, this may not present a major security concern if the data is encrypted. Unfortunately, open public wi-fi networks do not encrypt data, while common-password networks provide all public users access to the key to decrypt their own data as well as that transmitted by all others on the network. Such conditions can foster malevolent or illegal activities.

1. The paper refers to wi-fi as a broad socio-technical development, rather than Wi-FiTM as a trademarked technology 2. ACMA, "Strong signals: growing use of public Wi-Fi hotspots," (Sydney: Australian Communications Media Authority, 2014).
Despite its growing popularity, we know little about how consumers use public wi-fi, their understanding of the technology, including its security risks, and their expectations of service providers. We also know little about how providers determine their obligations to consumers in the 'light regulation' environment. Recent studies by the Australian Government AttorneyGeneral's Department and the Office of the Australian Information Commissioner suggest that Australians are concerned about online privacy and identity theft risks. ${ }^{3}$ However, those reports do not examine whether consumers appreciate the type and level of threat posed by different network access technologies, and whether they alter their online activity accordingly. This report presents an analysis of the first major Australian survey of users of public wifi networks. The report examines their online behaviour and perceptions and attitudes to data security risks, and analyses Terms \& Condition statements from 26 Australian public wi-fi networks (Appendix 3). It also draws on additional primary research conducted as part of the Australian Research Council-funded project, Public Wi-Fi as Urban Infrastructure the Australian Case (project number DP 150102818). This includes a face-to-face survey of people in Goulburn's (NSW) free community-run public wi-fi zone, and interviews with members of local and state government and community organisations involved in the development and provision of public wi-fi networks in Victoria, New South Wales, South Australia and Tasmania.

The report is intended to provide baseline data and inform policy development and awareness campaigns on the safe use of public wi-fi networks.

3. Attorney-General's Department, "Identity Theft Concerns \& Experiences Survey Report," (Canberra: Attorney-General's Department, 2012); OAIC, "Community Attitudes to Privacy Survey - Research Report," (Sydney: Office of Australian Information Commissioner, 2013) 
3. Public wi-fi regulation, risks and security

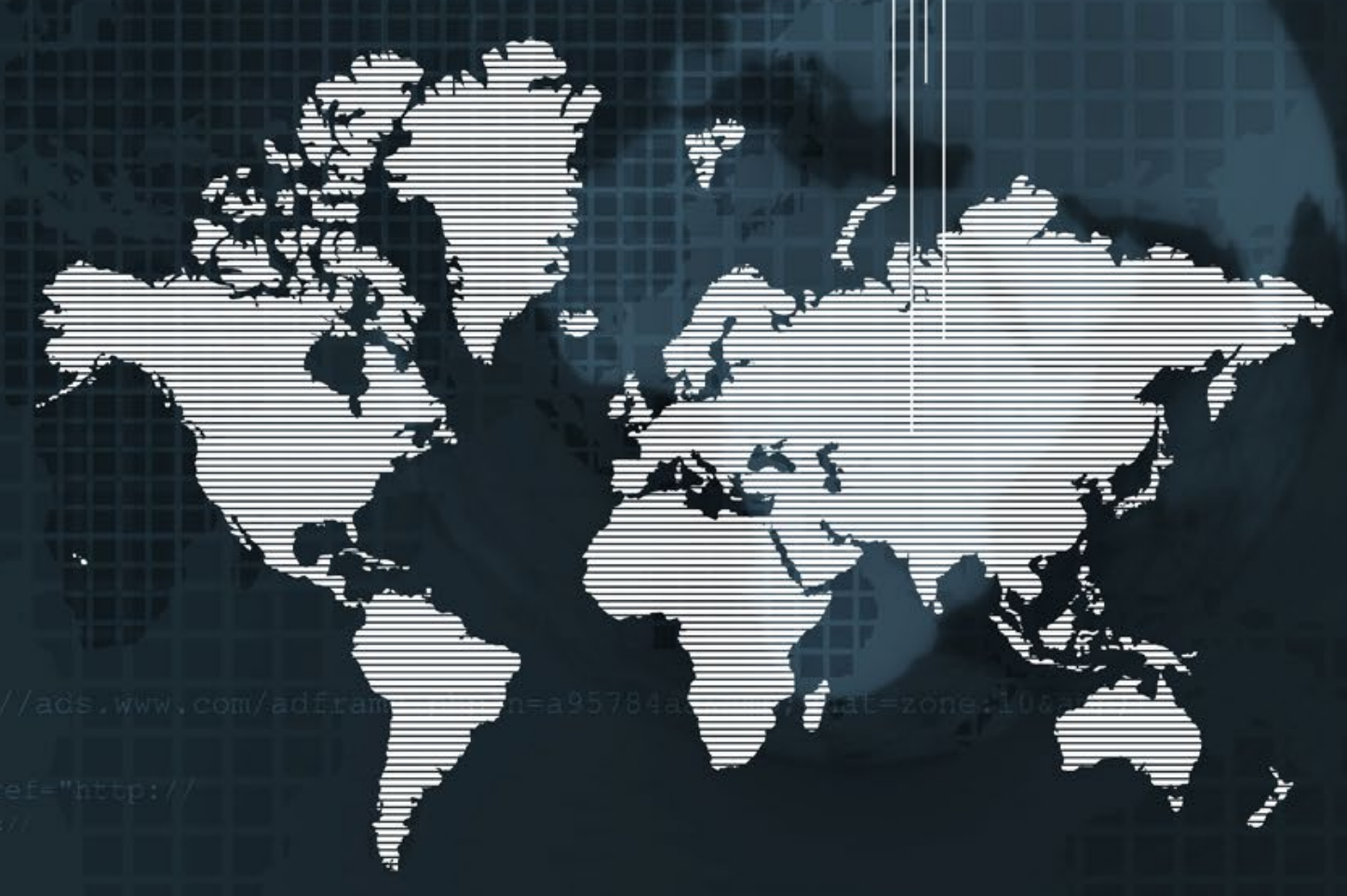




\section{Defining public wi-fi}

Judging by its extensive use in homes, wi-fi technology is well understood. More than four in five Australian households that are connected to the internet at home operate a wi-fi router, enabling wireless internet connectivity using the $2.4 \mathrm{GHz}$ and $5 \mathrm{GHz}$ portions of the radio spectrum. ${ }^{4}$ However, defining public wi-fi can be surprisingly complex. In this report, we take a broad view that public wi-fi constitutes wi-fi networks available freely (without direct cost) in public spaces and publicly-accessible spaces, whether provided by government, commercial, or community organisations. This covers wi-fi provided in shopping centres, cafes, public libraries, civic spaces, and so on. We include publicly-accessible wi-fi that may be freely available after purchase of goods, such as hotspots in Starbucks. We also include Telstra Air in the scope of this report. Telstra Air was trialled as a free and open network between November 2014 and June 2015 and since then has been provided as a value-add to the company's broadband and mobile contract services, as well as a casual, fee-for-service, standalone product. ${ }^{5}$

\section{How is public wi-fi regulated?}

Public wi-fi operates in a regulatory environment in Australia that covers both its physical properties, in using radio spectrum, and its content, as a form of telecommunications. At national government level, public wi-fi engages Commonwealth legislation covering radio spectrum management, telecommunications, competition and consumer protection, and privacy. Its provision may also be subject to state and local government planning frameworks, particularly with regard to the installation of access point (AP) infrastructure.

4. ACMA, "ACMA Communications Consumer Survey 2014 Dataset," (Melbourne: Australian Communications and Media Authority, 2014); "Australians' digital lives - Communications report 2013-14 series Report 1," (Melbourne: Australian Communications and Media Authority, 2015). See also Figure 8.

5. AAP, "Around 150 Telstra payphones are now transmitting Wi-Fi as part of a five-year plan to create two million public hotspots," SBS News (19 November 2014): Harry Tucker, "Telstra's nationwide Wi-Fi network is called Air and will launch on Tuesday," news.com.au (26 June 2015).
Figure 1: External wi-fi access points (APs)
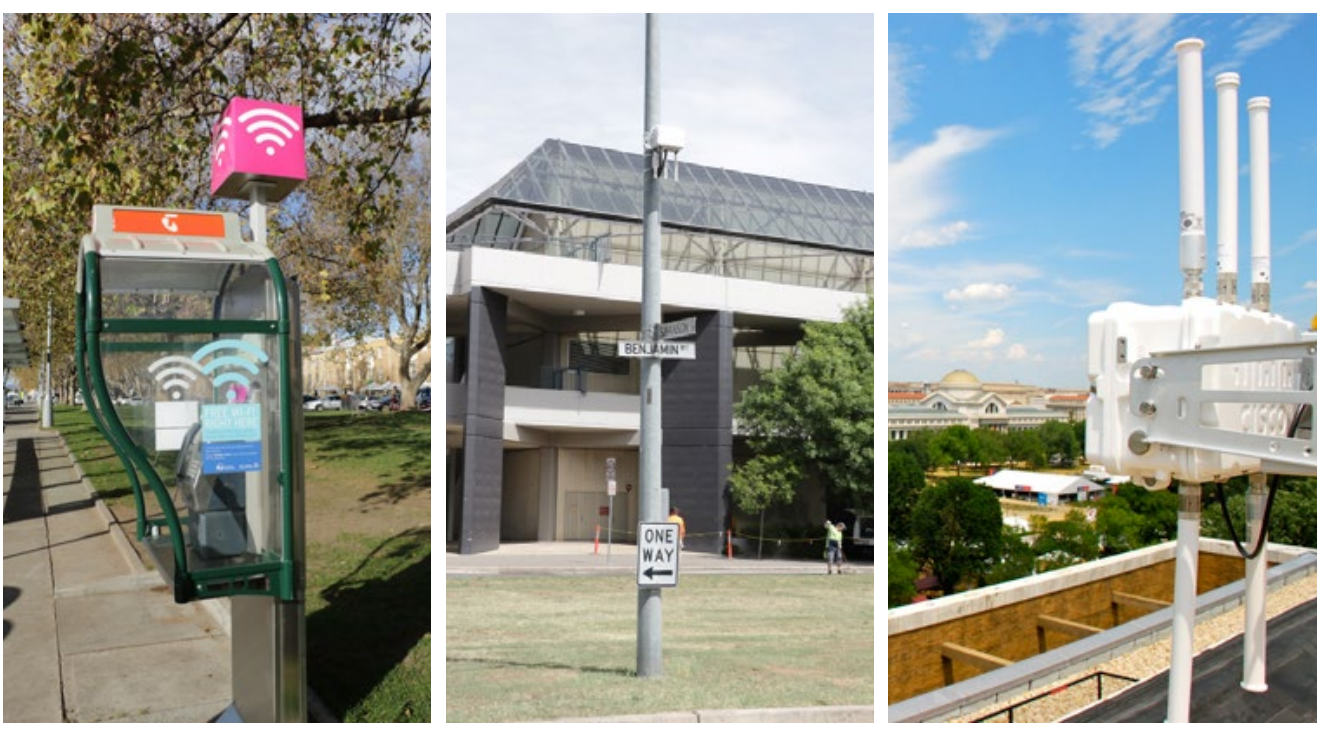

Source: dr_chriskwilson@flickr \& davidclow@flickr (creative commons)

Wi-fi networks are a type of wireless local area network (WLAN). Operators of WLANs are subject to radio communications licensing ${ }^{6}$ (covering equipment and spectrum use) and may be subject to telecommunications licensing ${ }^{7}$ (covering the supply of telecommunications services to the public). From a telecommunications industry perspective, the position of public wi-fi within the regulatory framework is considered somewhat unclear. ${ }^{8}$

Wi-fi mostly operates in the $2.4 \mathrm{GHz}$ spectrum band originally reserved by international agreement for industrial, scientific and medical use (the ISM band). The licensing conditions of this band seek to balance access, administrative efficiency and network interference by

6. Radiocommunications Act 1992 (Cth)

7. Telecommunications Act 1997 (Cth)

8. Communications Alliance: Public Wi-Fi Networks Industry Information Paper, 2012 http://www.commsalliance.com au/_data/assets/pdf_file/0010/36010/Public-Wi-Fi-Networks-information-paper-May-2012.pdf 
licensing the class of devices using the band (rather than individual devices or users) and limiting the power output of the device class. ${ }^{9}$ The scope of telecommunications licensing is less clear.

In summary, operating a public wi-fi network may require a carrier license and be subject to licensing regulations set out in the Competition and Consumer Act 2010 (Cth) ${ }^{10}$ (generally covering access and service standards). More typically, if a network is non-commercial, not considered to be providing a carriage service, or if it is in a single location (such as a café, shopping mall or airport), it is likely to be license exempt.

Other regulatory conditions may be imposed by state or local jurisdictions regarding public wifi infrastructure. These typically cover the installation of APs on a range of outside structures, including buildings, light poles (Figure 1). For instance, the issue of placing APs on heritage structures has arisen in the rollout of the Victorian government's VicFreeWiFi in Bendigo and Ballarat. ${ }^{11}$

While Commonwealth law relating to telecommunications has been described as complex and difficult to piece together ${ }^{12}$, the key element for our purpose is its prescription of an offence to intercept a communication passing over a telecommunications system "until it becomes accessible to the intended recipient of the communication"13

The use of a public wi-fi network to obtain personal information without the person's consent may also breach Australian privacy legislation. Such personal information might not be limited

. ACMA "Wireless LANS. what \& how fact sheet," (Sydney: Australian Communications and Media Authority, 2014); "Wireless LANs in the 2.4 GHz band FAQ," (Sydney: Australian Communications and Media Authority, 2016).

10. Competition and Consumer Act 2010 (Cth)

11. Interview - Economic Development Officer, City of Ballarat (conducted by CK Wilson) (Ballarat: 13 October, 2014) Interview - Economic Development Officer, City of Greater Bendigo (conducted by CK Wilson) (Bendigo: 6 October, 2014)

12. Tim Thomas and Craig Valli, "Mapping the laws which apply to intercepting wireless communications in a Western Australian legal context," in Australian Digital Forensics Conference (Perth: Edith Cowan University, 2015).

13. Telecommunications (Interception and Access) Act 1979 (Cth). to the content transferred via wi-fi, as the Google Street View episode suggests. In brief, between 2008 and 2010 Google harvested data from home and business wi-fi networks while obtaining photographs for its Street View service. The 'payload' (content) data surreptitiously collected by Google from unencrypted networks was found to be personal information by the Australian Privacy Commissioner who consequently concluded that Google had breached relevant provisions of Australia's Privacy Act-a determination that mirrored those made in the US, Canada and the UK. However, questions remain about whether the type of 'header' (technical/administrative) data collected by Google from APs in Australia, which includes Single Service Identifiers (SSID or network identifier), Media Access Control addresses (a device-level identifier) and signal strength details might also constitute personal information as has been determined in other national jurisdictions (Netherlands, France). ${ }^{14}$

\section{Public wi-fi insecurities}

Why are public wi-fi networks susceptible to hacking or interception? The answer lies in the balance that is struck between accessibility and security in network design.

The mass-marketization of wi-fi technology was marked by the launch of $\mathrm{Wi}_{\mathrm{i}} \mathrm{Fi}^{\mathrm{TM}}$ as a consumer brand identity for the IEEE802.11 wireless networking technical standard in $1999^{15}$ and the almost simultaneous release by Apple of a consumer wi-fi AP, the AirPort Base Station, and associated Airport wi-fi network interface card (NIC), for use with its computers ${ }^{16}$. This was soon followed by the advent of wardriving and similar practices aimed at locating and accessing open unencrypted networks ${ }^{17}$.

14. Mark Burdon and Alissa McKillop, "The Google Street View wi-fi scandal and its repercussions for privacy regulation, Monash University Law Review Vol. 39, no. No. 3 (2014).

15. Wireless Ethernet Compatibility Alliance "Wireless Ethernet Compatibility Alliance (WECA) Announces Independent Test Lab and Wi-Fi Technology Brand," news release, 15 September, 1999.

16. Alison Powell, "Community wi-fi, Resistance, and Making Infrastructure Visible," in The wireless spectrum : the politics, practices, and poetics of mobile media, ed. Kim Sawchuk, Barbara A. Crow, and Michael Longford (Toronto: University of Toronto Press, 2010).

17. Niloufer Selvadurai, Md Rizwanul Islam, and Peter Gillies "Unauthorised access to wireless local area networks: The imitations of the present Australian laws," Computer Law \& Security Review 25, no. 6 (2009).

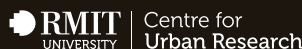


The encryption protocol initially released with the wi-fi standard, Wired Equivalent Privacy (WEP), was discovered to have major flaws. Wi-Fi Protected Access (WPA) was introduced by the IEEE in 2003 to bridge the WEP security gaps prior to formal adoption of WPA2 in in the IEEE802.11i standard in $2004^{18}$. Self-reported consumer data collected by wiggle.net reveals that it took time for WEP protected network devices to be replaced by WPA and WPA2 devices despite security concerns.

Public wi-fi introduces opportunities for APs to be compromised, for the traffic flow between wi-fi enabled devices to the APs to be captured, viewed or decrypted if WEP encryption is used, and for the wi-fi enabled devices to be attacked if the device is incorrectly setup. A key risk is the possibility that public wi-fi APs may have been compromised due to a direct attack or via an attack on some other network device or system that has access rights to the AP. By extension there is the possibility that the AP may have been incorrectly setup or suffered a configuration malfunction during startup.

It is not unusual for public wi-fi APs to be incorrectly configured, as many businesses and organisations providing networks lack appropriate technical expertise. As the wiggle.net chart shows, $8 \%$ of APs with a known security status are unsecured, and $12 \%$ have inferior WEP security. Essentially, one in five networks are not configured to use the best available security protocols.

The proliferation of wi-fi networks has led to the adaptation of wi-fi technical standards for mobile devices to facilitate roaming, minimising the need for re-authenticating at each network access point after the initial login. This is a feature of the $802.11 \mathrm{u}$ standard, released in 2011 and incorporated in software such as Passpoint and Hotspot 2.0. In addition to the convenience of automatic handover, the standard encourages use of a secure log-in through a pre-authentication process using the WPA-2 protocol.

18. Frank M Groom, Kevin M Groom, and Stephan Jones, Network and data security for non-engineers (Boca Raton: CRC Press, 2016). W Lemstra et al. "Crossing the chasm: the Apple AirPort" in The innovation journey of Wi-Fi: The CRC to Vic Hayes, and John Groenewegen (Cambridge: Cambridge University Press, 2011).

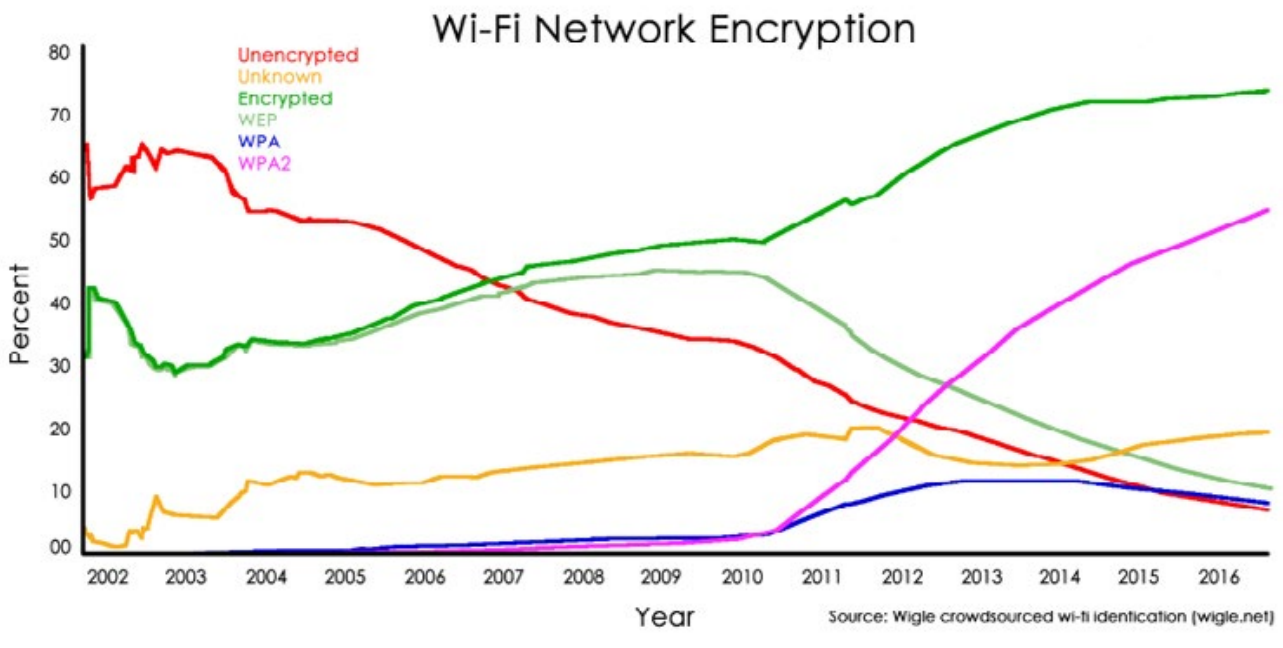

While Passpoint operates in the background, some mobile device manufacturers are incorporating software that details the status of wi-fi networks, alerting users that connection to an unencrypted network may be insecure. Additionally, several third-party apps purport to show whether there is interference with internet traffic over public wi-fi networks. However, some well documented 'spoofs' or experiments, detailed below, suggest the need for additional user safeguards and education.

\section{What do we know about risk and behaviours?}

There has been no systematic investigation into Australians' awareness of security risks associated with the use of public wi-fi, and there is a limited international literature on this subject. The following summarises some of the research that has been undertaken in this field.

Klasnja et al..$^{19}$ undertook an exploratory study on public understanding of wi-fi, and related

19. Predrag Klasnia et al., "When I am on Wi-Fi, I am fearless": privacy concerns \& practices in everyday Wi-Fi use," in Proceedings of the SIGCHI Conference on Human Factors in Computing Systems (Boston, MA, USA: ACM, 2009). 
privacy and security concerns, concluding that participants had limited awareness of the broadcast nature of wi-fi, while at the same time adopting risk-minimising practices that promoted a false sense of security. Once the threats were clearly understood, the study found, participants expressed a willingness to change practices. This study showed that users - perhaps understandably - had limited technical knowledge of encryption processes. Of more concern though, was the finding that some participants "simply trusted that financial and commercial institutions made perfectly secure Web sites". Many showed a high level of trust in network names as legitimate representations, while some believed that a firewall or anti-virus software on laptops secured wi-fi transactions. The study by Klasnja et al. supports work conducted by Kowitz and Cranor $^{20}$, which concluded that making activity on wireless networks more overtly visible to users alters their decision-making, and there was a desire amongst users for digital tools that could do so.

The potential hazards of public wi-fi use have been demonstrated by 'spoofing' exercises, where researchers set up networks with seemingly legitimate names and entice users to provide personal information or agree to bogus terms and conditions. Kindberg et al. (2008) deployed spoofed networks in two UK cafes and asked potential users to provide a unique network access PIN, to be sent to their mobile phones for authentication. Almost one-third of 361 people seeking to use the network provided their mobile numbers for this purpose.

In 2014, the UK Cyber Security Research Institute, backed by the European law enforcement agency Europol, conducted a spectacular spoof to highlight the lack of attention given by users to the terms and conditions (T\&C) governing network use. The researchers set up wi-fi hotspots in two London locations where users encountered a T\&C containing a so-called 'Herod' clause, promising free wi-fi if "the recipient agreed to assign their first born child to us for the duration of eternity". Six people signed up. ${ }^{2}$

20. Braden Kowitz and Lorrie Cranor, "Peripheral privacy notifications for wireless networks," in Proceedings of the 2005 ACM workshop on Privacy in the electronic society (Alexandria, VA, USA: ACM, 2005).

21. Tom Fox-Brewster, "Londoners Give Up Eldest Children in Public wi-fi Security Horror Show," The Guardian, 29 September 2014
App developers have responded to security concerns by designing a range of wi-fi security tools, including inSSIDer, Easy wi-fi, and AuthenticateMywi-fi. These tools provide ways of identifying, analysing and securing public networks, with varying levels of sophistication. Mobile phone manufacturers have also responded with proprietary tools to enhance visibility and awareness of wi-fi networks.

Network T\&Cs are a key consumer contact point which ostensibly provide an opportunity to guide decisions about access and use of public wi-fi networks. However, as the 'Herod' experiment cited above illustrates, the type of 'click-wrap' T\&Cs commonly deployed for public wi-fi and other digital products and services may lack effectiveness as a communication tool $^{22}$. What do public wi-fi T\&Cs say about network security, and how is this information presented on screen to the user? The following section discusses these issues.

\section{Public wi-fi network terms and conditions: serving whose interests?}

Access to public wi-fi in Australia and elsewhere is almost universally governed by a contract between the provider and the user that takes the form of non-negotiable terms and conditions (sometimes called terms of access, conditions or access, or similar) to which the user agrees electronically (generally by 'clicking' an 'agree' button). These click-wrap contracts are generally displayed, or accessible through, the network's 'splash' or first web page.

We analysed a convenience sample of 26 Australian public wi-fi networks T\&Cs provided by commercial, government and community institutions, to assess whether and how the contracts disclosed network security status and promoted informed use. We also compared this selection with a selection of nine T\&Cs used by public wi-fi providers in the USA and UK. Appendix 3 details the selection. The analysis highlighted two issues:

22. For an overview see Nancy S. Kim, Wrap contracts: foundations and ramifications (Princeton: Princeton University Press, 2013). 
1. T\&Cs varied considerably in length, readability and accessibility, particularly on mobile wireless devices. Several - notably those of community organisations and public libraries - are a few hundred words long and written in plain English. The longest text in the selection is around 6,800 words - half the length of this report. Some texts are so long and complex that they require considerable persistence and perhaps legal training to read and comprehend, yet their "boilerplate" character offers users no option other than to accept entirely in order to gain network access ${ }^{23}$.

2. 18 of the 26 Australian T\&Cs clearly advise users that communications on public wi-fi networks may be insecure. However, some network providers prioritise their risk and liability issues over consumer advice. The typical placement of warnings about network and communications security is towards the end of sometimes-lengthy documents. This raises questions about the extent to which users are effectively and fully informed of security risks. Conditions of access that seek to minimise provider risk may also be ineffective, impractical or even punitive. Young people are a particular target here. Several T\&Cs specify that people under 18 years of age may only access the network under adult supervision, and one specifies that only persons aged over 18 years may access the network.

A comparison of the T\&Cs used by Australian public wi-fi providers with T\&Cs used by a selection of providers in the USA and UK shows strong international correspondence. Several factors influence this uniformity: the on-line availability of generic T\&Cs, the presence in Australia of multinational public wi-fi providers, and the global trend to use click-wrap contracts.

Excerpts from four T\&Cs (see right) contrast documents that are oriented towards consumer information (the first two), and those seeking to minimise network provider risk and liability (the second two).

23. Margaret Jane Radin, Boilerplate : the fine print, vanishing rights, and the rule of law (Princeton: Princeton University Press, 2013).

66

The [name] wireless network is a non-secured network Information sent to and from your wireless device may be captured by anyone else with a wireless device. Please keep this in mind when accessing personal or business information.

66

We recommend that you do not use the Service, at any time, to undertake personal banking or disclose any personal information (such as account details, passwords, credit card details and bank account details).

\section{G6}

We do not warrant that any information, software or other material accessible through the Landing Page,

Terms of Service, is free of viruses, works, Trojan horses or other harmful components. While we take all due care in ensuring the privacy and integrity of the information you provide, the possibility exists that this information could be unlawfully observed by a third party while in transit over the internet or while stored on our systems.

We do not guarantee the security of this Wi-fi and unauthorised third parties may access Your electronic device and/or files or monitor Your connection while in transit over the internet or stored in Our systems. 


\section{Have government authorities alerted public wi-fi users of security issues?}

There has been considerable policy discussion and action in Australia and elsewhere on cybersafety issues focusing on access to inappropriate content and on-line behaviours ${ }^{24}$. However, there has been much less attention to cybersecurity at a user level25.

A 2002 Commonwealth Parliament House of Representatives inquiry into wireless broadband technologies was one of the first Australian studies to observe that the increasing use of WLANs posed security risks. The inquiry's report recommended that:

the ABA [Australian Broadcasting Authority], ACA [Australian Communications Authority] and law enforcement agencies establish a standing bureau (or working party) to maintain a watching brief on the potential for wi-fi and other ISM networks to be used for illegal activities ${ }^{26}$

Undertaken before the consumer uptake of internet-enabled hand-held mobile devices in Australia (generally acknowledged as occurring with the release of the iPhone in 2008), the focus of the inquiry was on the use of wireless technologies to provide 'last mile' broadband solutions, especially in rural and regional Australia. The inquiry's warning was prescient, but its recommendation was not specifically acted upon.

Four Australian government agencies (the Department of Communications and the

24. JJ Dooley et al., "Review of existing Australian and international cyber-safety research," (Perth: Child Health Promotion Research Centre, Edith Cowan University, 2009): Barbara Spears et al. "Research on youth exposure to, and management of cyberbullying incidents in Australia Part $C$. An evidence-based assessment of deterents to you and manam cyberbullying Appendix A: Literature review - International responses to youth cyberbullying and current Australian leg context," in Prepared for: Australian Government Department of Communications (Sydney: University of New South Wales, 2014).

25. Rachel Spacey et al. "Filtering wireless (Wi-Fi) Internet access in public places," Journal of Librarianship and Information Science (2015). DOI 10.1177/0961000615590693.

26. Information Technology and the Arts House of Representatives Standing Committee on Communications, "Connecting Australial Wireless Broadband," (Canberra: Parliament of Australia, 2002). p. 64.
Arts, the Australian Communications and Media Authority, the Australian Consumer and Competition Commission, and Office of the Children's eSafety Commissioner) provide warnings and information on public wi-fi security, with ACMA's illustrated online brochure the most accessible ${ }^{27}$. However, an online survey conducted in 2015 by the Department of Communications and the Arts as part of Stay Smart Online (SSO) Week suggested a low awareness of Australian government sources of information and online security: around half of the 125 survey respondents were unaware that SSO, the Children's eSafety Commissioner, or ACCC provided online security information. ${ }^{28}$

A benchmark for clear and concise consumer advice is the Victorian government, which provides public wi-fi networks in Melbourne, Ballarat and Bendigo. This advice is reproduced below:

"You should always take a couple of extra precautions while on any public WiFi network. When you use any public WiFi network, anyone in your vicinity can monitor the information passing between your device and the WiFi network if your connection is not encrypted.

Tips for staying safe on Public WiFi:

- Avoid sensitive transactions like banking.

- Maintain anti-virus protection.

- Install a trusted VPN app.

- Keep software updated.

- Have strong passwords.

Remember, no public WiFi is 100\% secure". 29

27. ACMA, "Wireless LANs in the $2.4 \mathrm{GHz}$ band FAQ."; Australian Government Communications and the Arts 2015 Australian Government Communications and the Arts, "Beware of online threats when using public Wi-Fi hotspots" "Australin Govenn Gove

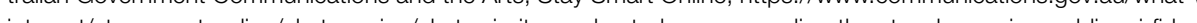
internet/stay-smart-online/alent-service/alert-pionty-modeate-be-aware-online-threats-when-using publc-wifi-hotspots.; ACMA, "Public Wi-Fi hotspots: food for thought!," Australian Communications and Media Authority, http://www. acma.gov.au/Citizen/Stay-protected/My-online-world/Staying-safe-online/public-wi-fi-hotspots-food-for-thought?

28. Department of Communications and the Arts, "Stay Smart Online Week Survey Results," Department of Communications and the Arts, https://www.communications.gov.au/departmental-news/stay-smart-online-week-survey-results.

29. Victorian Government: Public Wifi Safety. http://www.vic.gov.au/wifi/public-wifi-safety.htm 
However, advice on the secure use of public wi-fi networks has not been informed by welldesigned empirical research. This report presents an analysis of the first major Australian survey on this topic.

\section{What can consumers do to enhance their security when using public wi-fi?}

The most common threat at a public wi-fi location is the 'man-in-the-middle' attack where a cyber-criminal joins a public wi-fi network to attack victims' devices over the established connection to the public wi-fi access point, with the goal of redirecting traffic through the cyber-criminal's device or server somewhere on the internet. ${ }^{30}$

The risks associated with using public wi-fi can be mitigated by considering three factors:

(1) access point security,

(2) access point traffic security encryption, and

(3) consumer device setup.

If the access point has been compromised or has not been configured correctly in the first place, the traffic leaving the access point to travel further into the network can be redirected to a remote server or captured locally. Whilst the traffic from the consumer device to the access point may be securely encrypted if the access point itself has been compromised, the traffic travelling further into the network from the access point may not be encrypted and is therefore insecure. ${ }^{31}$

For users of a public wi-fi access point, whether or not the access point has been setup correctly or has been compromised is not something that is visible to the consumer's device. If the public wi-fi access point offers WPA-2 encryption security, traffic between wi-fi enabled

30. Dave Piscitello, "What is a Man in the Middle Attack?", ICANN, 2 Nov 2015, https://www.icann.org/news/blog/what is-a-manin-the-middle-attack

31. Mark Gregory and David Glance, Security and the Networked Society, Springer, USA, 2013, DOI: 10.1007/978-3310-02390-8, pp. 87 devices and the access point is relatively secure, but this has little bearing on the security of the public wi-fi access point itself. It is important therefore to consider only utilising public wi-fi offered by a public or private organisation or business that would be expected to correctly setup and check public wi-fi access points regularly.

To mitigate the risk of traffic being captured by a man-in-the-middle attack or through a compromised access point, a number of large corporations have recently introduced a HTTPS-only policy ${ }^{32}$, and have taken steps to reduce the use of the insecure HTTP protocol. So whilst traffic from a consumer device to an access point may be encrypted, the HTTP traffic leaving the access point and travelling further into the network may not be encrypted.

For a consumer, it is important to only access websites or online locations that are accessible using HTTPS. Currently web browsers do not provide a capability to block access to websites or online locations that utilise HTTP, although the most recent Google Chrome release is now displaying a "Not Secure" identifier next to HTTP URLs in the browser.

If accessing websites or online locations that utilise HTTP is unavoidable then currently the only effective way to mitigate the risk associated with public wi-fi traffic being compromised at the access point is to utilise a Virtual Private Network (VPN) ${ }^{33}$ connection either to a VPN provider or to a home Internet gateway that is configured to act as a VPN endpoint.

The VPN connection between a consumer device and a VPN endpoint provides an encrypted tunnel over which traffic can travel to a secure location before the traffic is delivered into the internet. However, it should be remembered that accessing websites or online locations with HTTP is not secure even when a VPN is used because the unencrypted HTTP traffic will leave the secure VPN before it gets to the target website or online location.

32. Liam Tung, "Apple tells iOS 9 developers to use HTTPS 'exclusively'”, CSO Online, 2016, http://www.cso.com.au/ article/577197/apple-tells-ios-9-developers-use-https-exclusively/; Liam Tung "Google kicks off Chrome plan to mark al

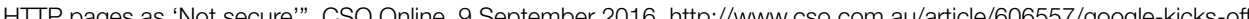
chrome-plan-mark-all-http-pages-secure

33. Mark Gregory, "Explainer: what is a virtual private network (VPN)?", The Conversation, 18 March 2013, http://theconversation.com/explainer-what-is-a-virtual-private-network-vpn-12741 
Access points may be setup with or without encryption for the traffic between consumer devices and the access point. It is important that consumer devices only connect to access points utilising WPA2 or a more recent security encryption. To ensure that only WPA2 or a more recent security encryption is used consumers should check their devices to setup WPA2 and to disable earlier security encryption options.

By far the most important action that a consumer can take to enhance their security when using public wi-fi is to ensure that their device is correctly configured and has anti-virus, antimalware, anti-exploit and anti-ransomware software installed. Notebooks, tablets and smart phones are often configured for use at home or in an office environment where it is necessary to connect to other systems and utilise network devices, such as printers. The standard configuration is not secure when the device is used to connect to public wi-fi.

Devices that are to be used to connect to public wi-fi should have the software patched and at the latest release version, to ensure that any identified security holes have been closed. Software patches should be applied to the device in a familiar environment, e.g. at home or in the office, and not at a public wi-fi location.

Many online systems today, including banks, Google Mail, and Facebook offer two-factor authentication ${ }^{34}$. It is important that when accessing the internet at a public wi-fi location twofactor authentication is used wherever possible because a compromised password does not provide access to a website or online location without the code provided through the second layer of protection. Utilising two-factor authentication for all websites and online locations that offer it is recommended at all times, irrespective of how the website or online location is being accessed.

It is the consumer's responsibility to be diligent in the use of HTTPS wherever possible and, to assist with reducing the difficulty of identifying if HTTPS is being used, seek out a web browser that provides a visual warning if HTTP is being used or provides a block on HTTP.

When moving between home or office networks and public wi-fi turn off network browsing, file and printer sharing and public folder sharing. It is highly likely that the device will be compromised if it provides an opening that can be exploited by someone else at the public wi-fi location or by a malicious application seeking insecure devices over the internet.

The device firewall should be turned on and checked regularly to ensure that it is operating correctly and applications have not opened ports through the firewall that should not be open when connected to public wi-fi.

Typically, devices come with inadequate security software installed and it is advisable to purchase and install security software before a device is connected to public wi-fi. Selecting appropriate security software and ensuring that it is kept up to date is one of the most important regular maintenance activities that consumers should carry out for all networkconnected devices.

A considerable number of vendors offer software packages that provide anti-virus, antimalware, anti-exploit and anti-ransomware protection, and it is possible to find vendors that offer family or home licenses that permit the software to be installed on multiple devices, including home computers, notebooks, tablets and smart phones.

34. NIST, "Digital Authentication Guideline", SP 800-63-3, National Institute of Standards and Technology, US Government, 2016, https://pages.nist.gov/800-63-3/

\section{DRMIT $\mid \begin{aligned} & \text { Centre for } \\ & \text { UNIVERSITY } \\ & \text { Urban Research }\end{aligned}$}




\section{Introduction}

This section analyses the survey data on public wi-fi use and user perceptions of public wi-fi network security.

\section{Methodology}

The survey sample design and selection was conducted by DiMarzio Research. The survey was conducted online and as such generates some sampling bias. Recent ABS data indicates that $85.9 \%$ of Australian households have internet access at home ${ }^{35}$. Some $97 \%$ of households with children aged under 15 years have a connection and $81.6 \%$ of households without children under 15 years had a connection.

\section{Weighting}

The dataset has been weighted using auxiliary variable data from the ABS census of population and housing.

\section{Findings}

\section{Device Ownership}

Respondents were asked to indicate if they had mobile devices that fell into a range of categories including mobile phones, tablets, laptops, handheld gaming devices, mobile broadband devices (MBD), and handheld gaming devices. Respondents could also specify ownership of 'other' mobile devices. All of the 'other' responses matched one of the established categories, and, as such, were recoded ( 1 × IPad as Tablets; 2 × IPods as Tablets, $1 \mathrm{x}$ Kindle - due to limited functionality and wi-fi only capacity this was recoded as a type of Handheld Gaming Device)

35. ABS, "8146.0 - Household Use of Information Technology, Australia," ed. Australian Bureau of Statistics (Canberra: Access via www.abs.gov.au, 2016).
Figure 2: Device Ownership

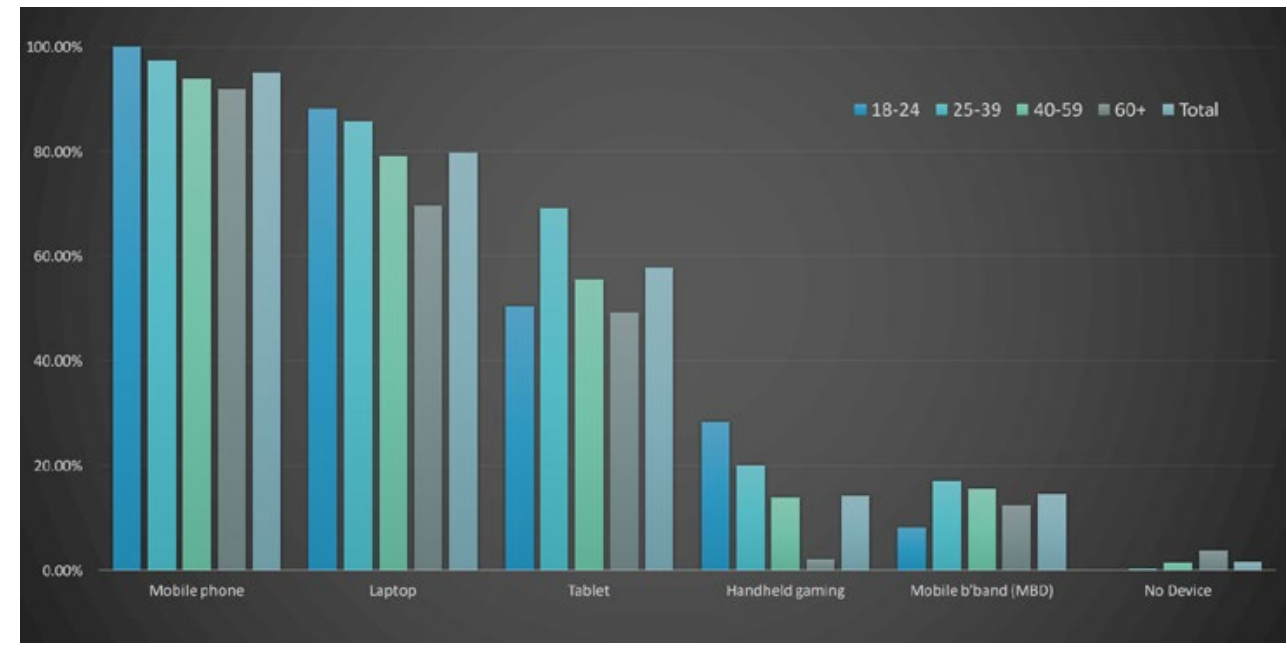

Figure 3: Device ownership by age

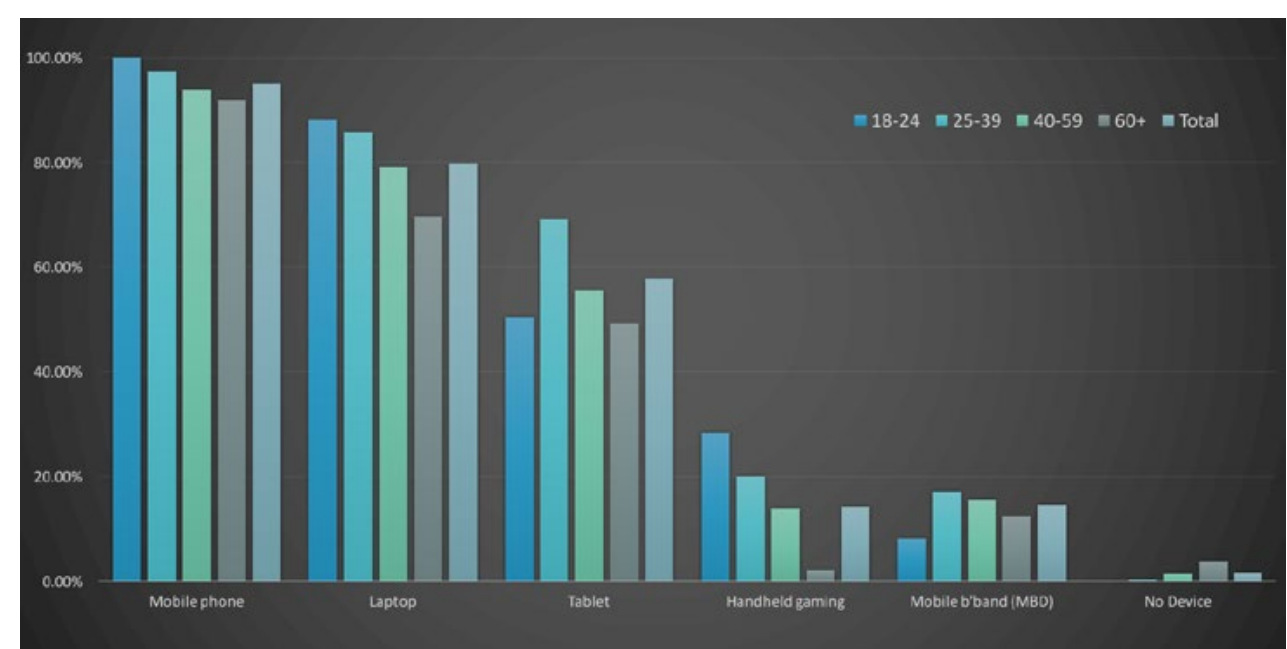

\section{DRMIT $\mid \begin{aligned} & \text { Centre for } \\ & \text { WNVirsory }\end{aligned}$ Urban Research}


Table 1: Average number of devices

\begin{tabular}{|cc|}
\hline Age & Av. Devices \\
\hline $18-24$ & 2.74 \\
\hline $25-39$ & 2.90 \\
\hline $40-59$ & 2.58 \\
\hline $60+$ & 2.25 \\
\hline Total & $\mathbf{2 . 6 2}$ \\
\hline
\end{tabular}

Table 2: Active mobile broadband devices (MBD)

\begin{tabular}{|ccc} 
& N & $\%$ \\
\hline MBD used as fixed-wireless & 60 & 25.3 \\
\hline MBD used as mobile device & 174 & 73.4 \\
\hline NA & 3 & 1.3 \\
\hline Total mobile-capacity MBD & 177 & 74.7 \\
\hline Total mobile broadband & 237 & 100.00
\end{tabular}

The most popular type of device was the mobile phone. Overall, 95\% of respondents had a mobile phone, with the vast majority (80\%) owning a smartphone (Figure 1). This result accords with data gathered by BuddeComm ${ }^{36}$, which found that by mid-2015 smartphone penetration was approaching 85\%. Laptops were owned by 4 in 5 respondents, while just under $58 \%$ had a tablet - the latter matching the $60 \%$ penetration rate found by BuddeComm

The penetration of mobile phones and laptops was highest amongst 18-24 year olds, and respondents in this group were, predictably, more likely to own handheld gaming devices. However, it was 25-39 year olds who were more likely to own tablets than other age groups (Figure 2).

36. BuddeComm, "Australia - Mobile Communications - Smartphones, Tablets and Handset Market," BuddeComm, http://www.budde.com.au/Research/Australia-Mobile-Communications-Smartphones-Tablets-and-Handset-Market.html.
Only 1.7 per cent of respondents did not have a mobile device, while 16.5 per cent had 4 or more devices. The average number of devices owned by respondents was 2.62. The largest number of devices on average was owned by 25-39 year olds (Table 1).

\section{Mobile Broadband}

Mobile broadband emerged as a significant new broadband connectivity option in the late 2000s. By the end of 2008 there were over 1 million Australian subscribers, accounting for $17 \%$ of internet connections. This connectivity type continued to grow rapidly and peaked at $50 \%$ of internet connections (excluding mobile handsets) in $2013 .{ }^{37}$ Since that time there has been a slight decline in the number of subscribers, offset by the increasing penetration of smart phones that facilitate both direct internet connectivity and use as a mobile hotspot. Indeed, by mid-2014 data downloads over mobile handsets were greater than wireless broadband downloads ${ }^{38}$.

Overall, $19.8 \%$ of respondents owned a 'live' mobile broadband device (where the device was actively connected to a data plan).

Mobile broadband devices can sometimes be used as a fixed-wireless alternative to home/ office wired broadband. Given this study is interested in mobile device use, respondents were asked to clarify if the mobile broadband was generally used to access the internet away from home/work. Approximately three quarters of respondents indicated they used their mobile broadband device outside the home (Table 2).

37. ABS, "8153.0 - Internet Activity, Australia," ed. Australian Bureau of Statistics (Canberra: Access via www.abs.gov. $\mathrm{au}, 2015)$.

8. ACMA, "Communications Report 2013-14," in Communications Report: previoulsy Telecommunications Performance Report (Melbourne: Australian Communications and Media Authority, 2014). 


\section{Cellular monthly mobile data allowances}

Respondents were asked to indicate the monthly data allowance they had for each of three compatible mobile devices they might own - mobile phones, tablets and active MBD (it is important to note that the 60 respondents using MBD in a fixed capacity are excluded from this analysis - see Table 2). Overall, only 42 of the 1,200 respondents (3.5\%) did not have any of these three types of mobile device.

Data allowance - level of awareness

In total, $73.7 \%$ of respondents with a compatible device could identify the size of at least one of their data plans, while $8.5 \%$ indicated that they had undertaken online activities using cellular networks in the previous three months but did not know the size of a data plan they have access to (Figure 3).

Figure 4: Monthly mobile data allowance overview

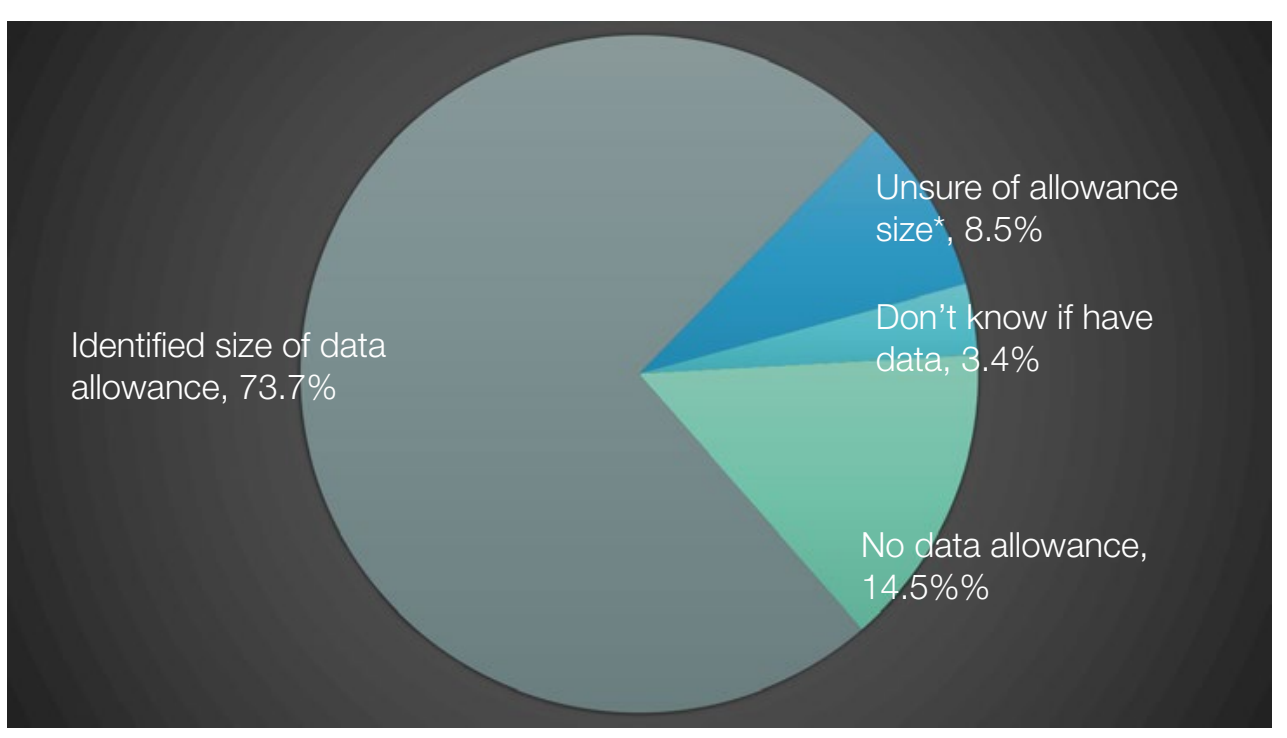

Base: Respondents with a compatible device (n: 1,158)

‘These respondents selected 'Don't Know' when presented with options of plan sizes but indicated elsewhere in the survey that they had used mobile data to undertake online activities. 3.4\% of respondents (39) selected 'Don't Know' and indicated they had not used mobile data to undertake online activities.
Overall, $14.5 \%$ of respondents definitively indicated that they had no data plan, while a small number of respondents had not used cellular networks to conduct online activities in the previous three months but could not be certain whether they had a data plan.

Mobile data allowance by device type

Owners of mobile phones, tablets and MBD were asked to select one of seven data allowances associated with the device, ranging from no data to 8 gigabits or more. The ranges were determined on the basis of common retail mobile data plans available at the time of the survey.

An examination of this data reveals that less than one in five respondents with a mobile phone do not have a data allowance for the device, while half of all tablet owners do not have an associated mobile data plan (Table 3). While there was a relatively even spread of data allowances on tablets from less than $500 \mathrm{mb}$ to more than 8 gigabits, mobile phone plans held by respondents tended to be in the moderate $500 \mathrm{mb}-4 \mathrm{~GB}$ range. Given the specific functionality of MBD it is not surprising that the majority of allowances held were in the higher range of 4 plus gigabits per month

Largest mobile data allowance - any device owned

The data was analysed to determine the largest mobile data plan held by an individual across all compatible mobile devices. Here, the dataset excludes the 137 respondents that did not know if they had a plan or the size of that plan and the 168 respondents that indicated they did not have a data plan for any of their devices. The total sample size for this analysis is 854 .

The data reveal that half of all mobile data subscribers have maximum plan sizes on any of their devices of less than 2GB per month, and more than one quarter less than $1 \mathrm{~GB}$ (Figure 4). For just over one in ten subscribers, the largest mobile data allowance held on any single device is less than $500 \mathrm{mb}$ per month.

Largest mobile data allowance by age

Examining the data by age we see that it is younger (18-24) and older (60+) people that tend

\section{- RMIT $\mid \begin{aligned} & \text { Centre for } \\ & \text { UNIVERSITY }\end{aligned}$}


Table 3: Mobile allowances by device type

\begin{tabular}{|c|c|c|c|c|c|c|}
\hline & \multicolumn{2}{|c|}{ Mobile phone } & \multicolumn{2}{|c|}{ Tablet } & \multicolumn{2}{|c|}{$\begin{array}{c}\text { Mobile } \\
\text { broadband } \\
\text { device (MBD) }\end{array}$} \\
\hline & $\mathrm{N}$ & $\%$ & $\mathrm{~N}$ & $\%$ & $\mathrm{~N}$ & $\%$ \\
\hline Don't know & 31 & $2.7 \%$ & 20 & $2.9 \%$ & 0 & $0.0 \%$ \\
\hline No data allowance & 187 & $16.4 \%$ & 345 & $49.8 \%$ & $\star \star$ & ** \\
\hline Unsure of allowance size & 105 & $9.2 \%$ & 56 & $8.1 \%$ & 21 & $11.8 \%$ \\
\hline Less than $500 \mathrm{mb}$ & 94 & $8.2 \%$ & 30 & $4.3 \%$ & 11 & $6.2 \%$ \\
\hline $500 \mathrm{MB}$ to $999 \mathrm{MB}$ & 144 & $12.6 \%$ & 40 & $5.8 \%$ & 14 & $7.9 \%$ \\
\hline 1 to $1.99 \mathrm{~GB}$ & 217 & $19.0 \%$ & 45 & $6.5 \%$ & 28 & $15.7 \%$ \\
\hline 2 to $3.99 \mathrm{~GB}$ & 173 & $15.2 \%$ & 51 & $7.4 \%$ & 25 & $14.0 \%$ \\
\hline 4 to $7.99 \mathrm{~GB}$ & 111 & $9.7 \%$ & 41 & $5.9 \%$ & 36 & $20.2 \%$ \\
\hline 8 or more GB & 78 & $6.8 \%$ & 64 & $9.2 \%$ & 43 & $24.2 \%$ \\
\hline Have data & 922 & $80.9 \%$ & 327 & $47.2 \%$ & 178 & $100.0 \%$ \\
\hline Total & 1,140 & $100.0 \%$ & 693 & $100.0 \%$ & 178 & $100.0 \%$ \\
\hline
\end{tabular}

${ }^{*} A$ number respondents (26) with a MBD indicated that they did not have a monthly data allowance. This result may reflect a combination of ownership of inactive $M B D$ and respondent error. The analysis of data allowances excludes these respondents.

to have relatively small data plans (under $1 \mathrm{~GB}$ per month) (Figure 5).

Aggregate mobile data allowance across all devices

A second analysis was conducted to compose an estimate of aggregate mobile data accessible to respondents over all compatible devices. To compute this aggregate variable for each respondent with at least one mobile data plan the midpoint of the data allowance range selected for each device was determined (with $8000 \mathrm{mb} / 8 \mathrm{~GB}$ designated for the $8 \mathrm{~GB}$ plus
Figure 5: Largest allowance

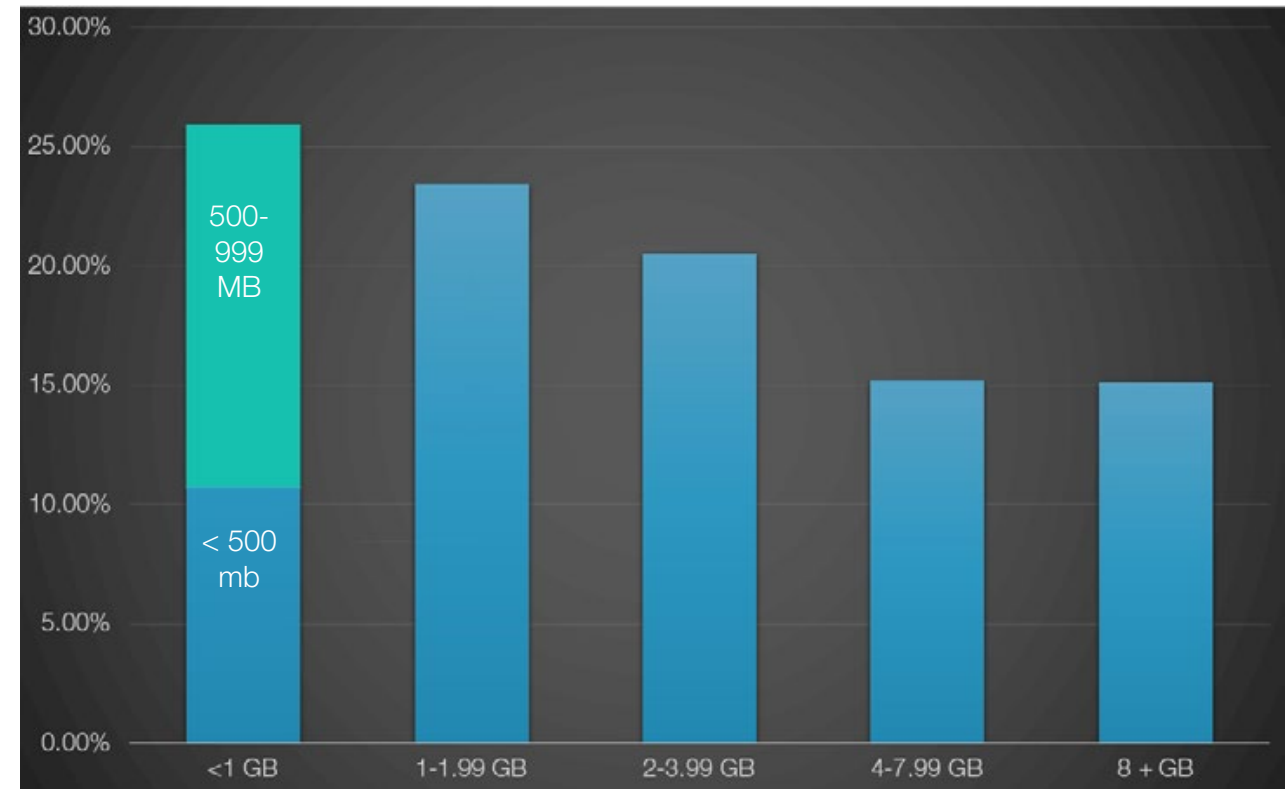

Base: Respondents with a specified monthly data allowance (n: 854)

category) and added together. Table 4 shows the midpoints assigned.

The aggregates were then reassigned to new ranges to simplify data presentation (Figure 6).

Table 4: Mobile data range midpoints

\begin{tabular}{|cc|}
\hline Range in Survey & Midpoint for aggregation \\
\hline Less than $500 \mathrm{mb}$ & $250 \mathrm{mb}$ \\
\hline $500 \mathrm{MB}$ to $999 \mathrm{MB}$ & $750 \mathrm{mb}$ \\
\hline 1 to $1.99 \mathrm{~GB}$ & $1500 \mathrm{mb}$ \\
\hline 2 to $3.99 \mathrm{~GB}$ & $3000 \mathrm{mb}$ \\
\hline 4 to $7.99 \mathrm{~GB}$ & $6000 \mathrm{mb}$ \\
\hline 8 or more GB & $8000 \mathrm{mb}$ \\
\hline
\end{tabular}


The data show that one in five mobile data subscribers have access to less than $1 \mathrm{~GB}$ of mobile data per month. The majority of subscribers (63.4\%) had access to less than 4 GB per month.

Approximately one in three younger subscribers had access to less than $1 \mathrm{~GB}$ of mobile data per month (Figure 7). Interestingly, subscribers over 60 years of age were overrepresented amongst those with access to under $1 \mathrm{~GB}$ per month and amongst those with an aggregate allowance over $12 \mathrm{~GB}$ per month.

Activities on cellular networks

Mobile data subscribers were asked to indicate whether they had undertaken one of 12 distinct types of online activity in the prior three months using their mobile data. Respondents could also nominate an 'other' distinct activity type. Less than two per cent of respondents

Figure 6: Largest data plan held by age (\% of age group plan holders)

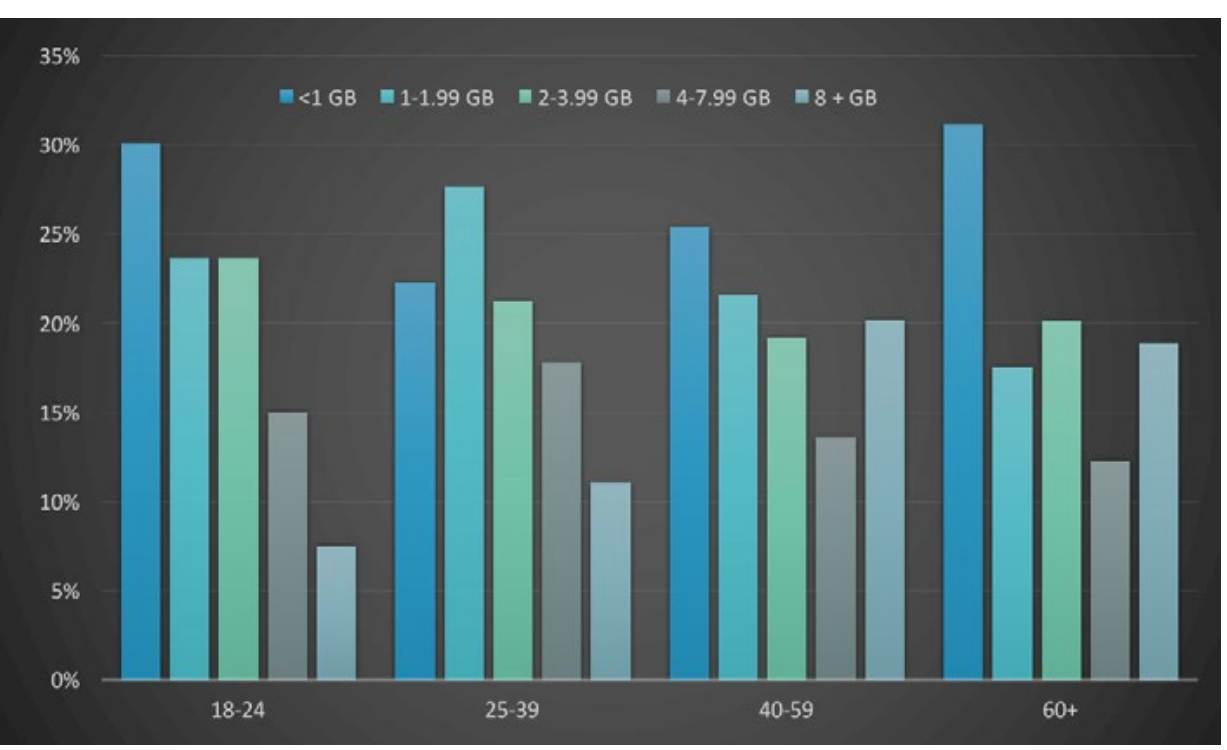

Base: Respondents with a specified monthly data allowance (n: 854)
Figure 7: Aggregate data across devices (\% of plan holders)

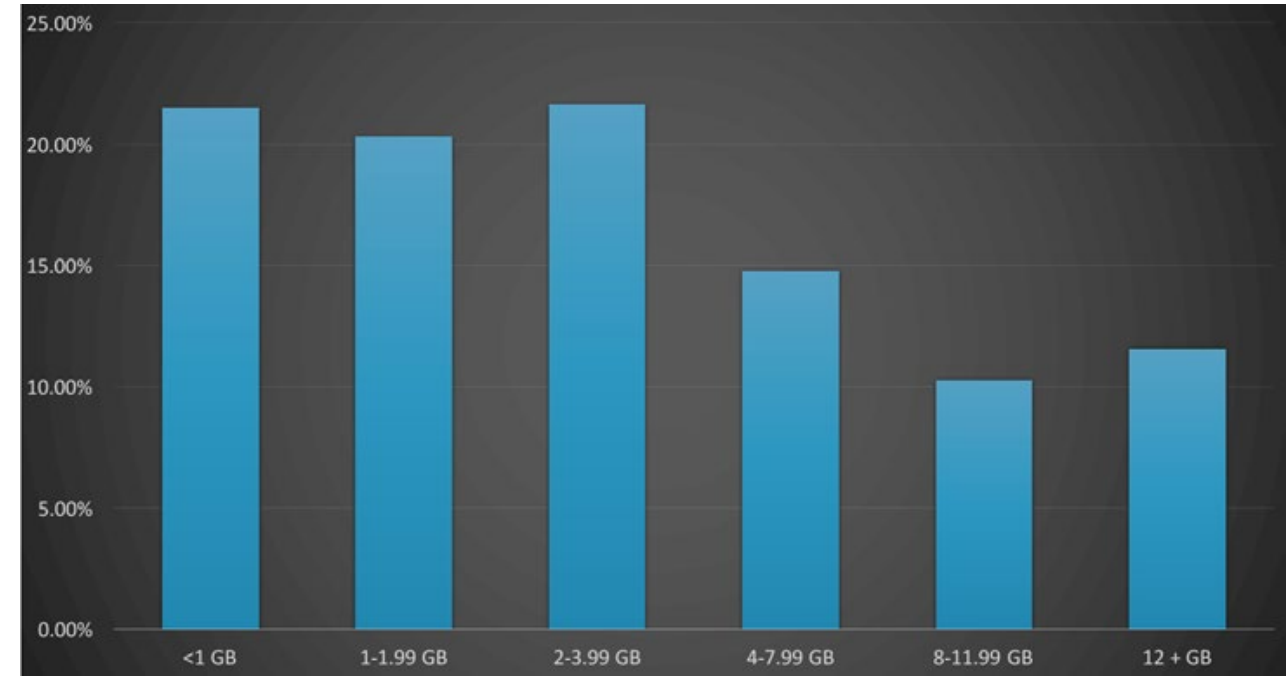

Base: 853 resp. with a specified monthly data allowance

Figure 8: Aggregate data across devices by age (\% of age group plan holders)

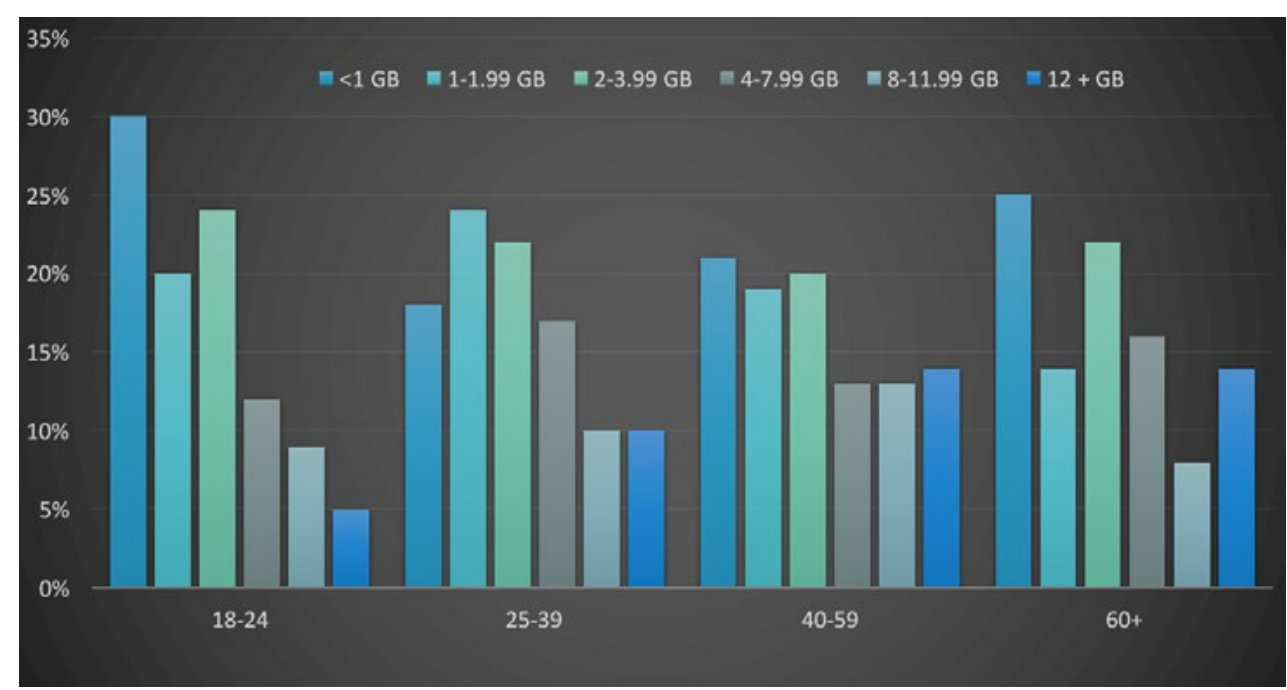

Base: Respondents with a specified data allowance (n: 854)

\section{DRMIT | Centre for}


did so, with the majority of these using online maps and a few nominating use of games and 'Apps'.

Table 5 ranks the twelve activity types on the basis of the percentage of respondents with access to mobile data that had undertaken them. The most common activity was general internet browsing, undertaken by more than four in five respondents with mobile data.

Social networking, email and more instant forms of messaging were a popular undertaking. Interestingly, more than two thirds of mobile data subscribers had used this form of internet connectivity for internet banking.

On average, mobile data subscribers undertook 6.4 distinct online activities in the prior three months. Younger subscribers engaged in a greater range of activities than those over 40 years of age (Table 6).

Table 5: Online activities conducted on mobile cellular networks in previous 3 months

\begin{tabular}{lcc}
\hline Online activity & $n$ & $\%$ \\
\hline 1. General internet browsing & 831 & $83.9 \%$ \\
\hline 2. Sending or receiving personal emails & 760 & $76.8 \%$ \\
\hline 3. Social networking (i.e. Facebook / Twitter) & 694 & $70.1 \%$ \\
\hline 4. Internet banking & 665 & $67.2 \%$ \\
\hline 5. Chat or instant messaging (e.g. Texting, Snapchat) & 647 & $65.4 \%$ \\
\hline 6. Downloading or uploading documents & 510 & $51.5 \%$ \\
\hline 7. Paying for goods or services using a credit card & 468 & $47.3 \%$ \\
\hline 8. Paying for goods or services using Paypal & 433 & $43.7 \%$ \\
\hline 9. Using work services (e.g. work email / file sharing) & 370 & $37.4 \%$ \\
\hline 10. Downloading or uploading audio or video files & 363 & $36.7 \%$ \\
\hline 11. Streaming audio / video (e.g. live sport / Spotify) & 317 & $32.0 \%$ \\
\hline 12. Skype/FaceTime/Other VOIP & 290 & $29.3 \%$ \\
\hline No activities & 71 & $7.2 \%$ \\
\hline Total with data plan & 990 & $\mathbf{1 0 0 . 0} \%$
\end{tabular}

Base: Respondents with a data subscription (excludes 168 indicating 'no plan' and 42 without devices)
Younger subscribers (18-24 years) were significantly more likely to engage in chat or instant messaging than older age groups and, along with the 25-39 year age group, were heavy users of social networking applications (Table 7). More than four in five mobile subscribers in the 25-39 year age group engaged in internet banking over mobile networks - a significantly larger proportion than the dataset average. Older subscribers (60+) recorded lower than average use rates for each of the 12 activities. They were significantly under-represented amongst social networking and chat/instant messaging users, and, unsurprisingly, work service users.

Table 6 Average number of activity types conducted on mobile cellular networks in previous 3 months owned by age

\begin{tabular}{|cc}
\hline Age & $n$ \\
\hline $18-24$ & 7.3 \\
\hline $25-39$ & 7.9 \\
\hline $40-59$ & 5.8 \\
\hline $60+$ & 4.5 \\
\hline Total & $\mathbf{6 . 4}$ \\
\hline
\end{tabular}

Base: respondents with a data plan (excludes 168 indicating 'no plan' and 42 without devices)

\section{Wi-fi at home}

Wi-fi is now an established domestic and workplace technology in Australia. Almost $87 \%$ of respondents indicated they have a home wi-fi network, a penetration figure consistent with that reported in 2014 by the ACMA. ${ }^{39}$

The majority of home networks (93\%) are password protected and respondents were generally confident that their networks were secure. More than four in five home network owners felt their wi-fi was very secure or fairly secure (Figure 8).

39. "ACMA Communications Consumer Survey 2014 Dataset." http://acma.gov.au/theACMA/acma-communications-consumer-survey-data-2014 
Table 7: Online activities conducted on mobile cellular networks in previous 3 months by age

\begin{tabular}{|llllll|}
\hline Online activity & $18-24$ & $25-39$ & $40-59$ & $60+$ & Total \\
\hline General internet browsing & $87.0 \%$ & $92.1 \%$ & $81.8 \%$ & $71.4 \%$ & $83.9 \%$ \\
\hline Sending or receiving personal emails & $79.0 \%$ & $84.4 \%$ & $73.7 \%$ & $67.7 \%$ & $76.8 \%$ \\
\hline Social networking (i.e. Facebook / Twitter) & $86.0 \%$ & $86.2 \%$ & $62.6 \%$ & $46.9 \%$ & $70.1 \%$ \\
\hline Internet banking & $74.0 \%$ & $83.2 \%$ & $59.5 \%$ & $49.5 \%$ & $67.2 \%$ \\
\hline Chat or instant messaging (e.g. Snapchat) & $88.0 \%$ & $75.0 \%$ & $60.3 \%$ & $45.8 \%$ & $65.4 \%$ \\
\hline Downloading or uploading documents & $58.0 \%$ & $63.8 \%$ & $46.6 \%$ & $35.4 \%$ & $51.5 \%$ \\
\hline Paying for goods or services with credit card & $48.0 \%$ & $60.0 \%$ & $41.9 \%$ & $33.9 \%$ & $47.3 \%$ \\
\hline Paying for goods or services using Paypal & $45.0 \%$ & $55.6 \%$ & $38.3 \%$ & $32.3 \%$ & $43.7 \%$ \\
\hline Using work services (e.g. work email) & $41.0 \%$ & $48.8 \%$ & $36.0 \%$ & $17.2 \%$ & $37.4 \%$ \\
\hline Downloading or uploading audio or video & & & & & \\
files & $37.0 \%$ & $47.9 \%$ & $34.4 \%$ & $20.8 \%$ & $36.7 \%$ \\
\hline Streaming audio / video (e.g. Spotify) & $41.0 \%$ & $49.4 \%$ & $23.5 \%$ & $13.0 \%$ & $32.0 \%$ \\
\hline Skype/FaceTime/Other VOIP & $28.0 \%$ & $40.9 \%$ & $22.3 \%$ & $21.9 \%$ & $29.3 \%$ \\
\hline
\end{tabular}

Base: respondents with a data subscription (excludes 168 indicating 'no plan' and 42 without devices)

Figure 9: Perceptions of home wi-fi security

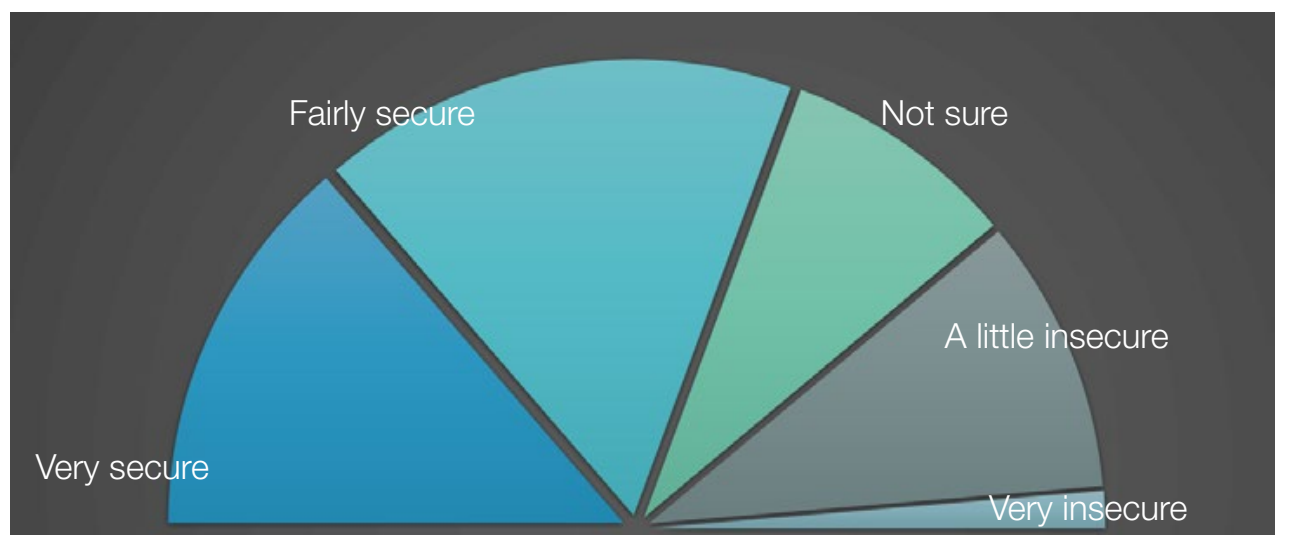

Base: wi-fi network operators (n: 1,041)

\section{Public wi-fi access}

After being presented a definition of public wi-fi as "any wifi network made available to the general public (either paid or free) by a business, government or community organisation, but NOT wi-fi made available at your workplace" 40 , respondents were asked a series of questions about their public wi-fi use.

Public wi-fi users

Overall, 56.4\% of respondents used a public wi-fi service in the previous three months (Figure 10), equating to 10.4 million Australians. More than one in five people (4 million Australians) are very frequent users, accessing public wi-fi networks at least weekly.

Non-users of public wi-fi (description of reasons)

The $43.6 \%$ of people that did not access public wi-fi in the previous three months were asked to describe the main reason they had not done so. Each 'free text' response was examined and reclassified according to keywords into one of ten categories (Table 8). Where an individual included multiple reasons these were separated and counted as distinct responses, yielding a total of 601 non-use reason comments - as such the sum of Table 8 exceeds $100 \%$.

More than half of all non-users indicated that they had no need to use public wi-fi without being specific about that lack of need. The second most common reason for non-use relates to concerns about the security of public wi-fi. One in six non-users were worried that using public wi-fi might compromise their security, with a range of references to 'security', 'trust', 'hackers', and 'privacy' (Figure 10).

One in six non-users made mention of their preference to use mobile data rather than public wi-fi, with a further $8.2 \%$ highlighting that prior experiences with poor quality wi-fi had put

40. At the beginning of the survey, respondents were presented this definition alongside the definition of home wi-fi (see Appendix 2) 
Figure 10: Access to public wi-fi

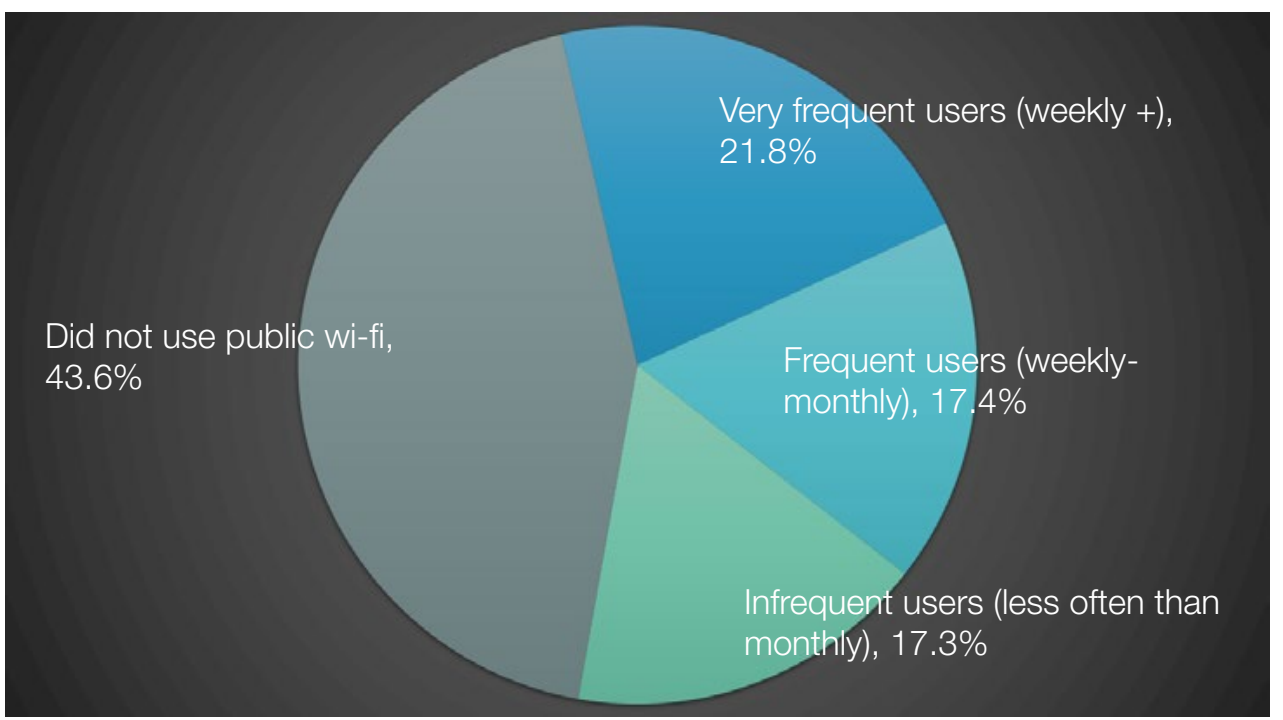

Base: All respondents (n: 1,200)

them off using it again. These quality of service issues included difficulties in logging in, slow speeds, drop-outs and being spammed by providers that had required an email address be provided to use the service.

Public wi-fi use by access location

The most popular access location was cafes, restaurants, fast food and other food/beverage outlets (Table 8). Shopping centres were also significant public wi-fi providers - particularly for older people (Table 9).

Over one in six people had accessed wi-fi in public spaces, such as parks or city squares. The provision of wi-fi in such spaces by Australian local and state governments has rapidly expanded over the past three years. ${ }^{41}$ In addition, there has been some investment in provision of wi-fi on public transport services. More than one in ten people accessed the

41. Ian McShane, C K Wilson, and Denise Meredyth, "Broadband as Civic Infrastructure - The Australian Case "Media International Australia 151, pp. 127-136, (2014). internet on such services in the past three months.

Public libraries, where local and state governments have long invested in public internet provision, continue to play an important role in public internet provision. Almost $13 \%$ of people used public library wi-fi services in the past three months. This access was particularly important for younger people $-37.2 \%$ of young public wi-fi users had connected through public libraries in the previous three months.

Table 8: Reasons for not using public wi-fi

$\begin{array}{lc}\text { Reason } & \begin{array}{c}\% \text { of } \\ \text { non users }\end{array} \\ \text { No identified need to use such a service } & 52.4 \% \\ \text { Concerned about security of public wi-fi } & 16.7 \% \\ \text { Preference for mobile data use } & 15.9 \% \\ \text { Lack of provision } & 8.4 \% \\ \text { Specific quality of service concerns (connection difficulty, } & 8.2 \% \\ \text { speed, data limits, spam) } & 7.4 \% \\ \text { Only access internet at home or work } & 4.2 \% \\ \text { No device to conveniently use public wi-fi } & 3.2 \% \\ \text { Knowledge of how to access public wi-fi } & 1.2 \% \\ \text { Use when traveling (but not in prior 3 months) } & 3.2 \% \\ \text { Not stated }\end{array}$

The Telstra Air network which has been variously freely open to the public and promoted as freely available (albeit to its customers only) since late 2014 was used by $15.8 \%$ of people in the three months prior to the survey, with higher use by younger age groups (18-24, 25-39). Telstra's Air network consists of both wireless access points retrofitted to the public payphone network and the addition of a 'public' channel to the wi-fi modems owned by Telstra home broadband customers that have signed up for the Telstra Air service ${ }^{42}$.

42. Ian McShane, C K Wilson, and Mark Gregory, "Customers to provide the hotspots in Telstra's new Wi-Fi plan (Commentary)," The Conversation (2014) https://theconversation.com/customers-to-provide-the-hotspots-in-telstrasnew-wi-fi-plan-32663. 
Figure 11: Selected non-use reason descriptions

Concerned about security of public wi-fi

- I do not believe it is secure; risk of hacking

- I do not trust public wi-fi security I have heard that it is a good way to get your personal information stolen etc

- I do not trust the security or trust other people sharing the network

- I feel that my privacy is insecure using a public one

- I work in IT and don't trust public wi-fi networks with my data

- Not certain of its security and whether it is open to 'hacking' of personal information

- Prefer security of $3 \mathrm{~g} / 4 \mathrm{~g}$

Specific quality of service concerns (connection difficulty, speed, data limits, spam)

- Too hard to work out how to log in

- I find it also can take too long to connect \& then be glitchy so I would rather use 3G

- I have got 4G on my devices. I don't need to use public slow internet

- It's either too expensive or too time consuming to connect to something that ends up being a crap service

- Because I get bombarded with spam emails from whoever the site owner is... Preference for mobile data use

- Because I have unlimited internet on my phone. Therefore do not require any other wi-fi

- When I did have the need I find the 3G/4G network works better than free WI-FI offered.

- $\quad$ Easier just to keep my phone connected to standard $3 G$ internet than find wi-fi locations

Knowledge of how to access public wi-fi

- I don't know how to do it.

- I wouldn't know how to use it

Lack of provision

- I live in an area which does not offer that many and it is usually easier to just leave the settings as they are for $4 \mathrm{G}$.

- Free public wi-fi is not frequently available in the places I visit, I use my data when out

- ... I live in the country region not the city so there are not many to start with and they are weak, not worth using
Some of the 'other' access locations nominated by respondents include caravan parks, museums, zoos, hospitals, the blood bank and financial institutions, a clear indicator of the importance of wireless connectivity to broad range of retail and service providers.

Public wi-fi use by age

Public wi-fi use by age

Young people are particularly heavy users of public wi-fi (Figure 12). Four in five people aged 18-24 years accessed public wi-fi in the previous three months, and one in three used this form of internet access at least once per week.

\section{Public wi-fi use: device types}

The most common type of device used to access public wi-fi was the mobile phone, particularly for younger users (Table 10, Table 11). Four in five of those that accessed public wi-fi networks in the previous three months did so using a mobile phone.

Laptops and tablets were the access device used by $23 \%$ of public wi-fi users, with younger (18-24) users more likely to use laptops and older users (60+) more likely to use tablets.

Younger users were more likely to use multiple devices to access public wi-fi. Almost 35\% of 18-24 year old public wi-fi users accessed such networks using two or more different devices in the previous three months (Figure 12).

\section{Activities conducted on public wi-fi networks}

Public wi-fi users were asked to indicate whether they had undertaken one of 12 distinct types of online activity in the previous three months using public wi-fi. Respondents could also nominate an 'other' distinct activity type. Five per cent of respondents did so, with the majority identifying software/App updates, and a small number using online maps, online games and checking for transport information.

\section{DRMIT $\mid \begin{aligned} & \text { Centre for } \\ & \text { UNversir }\end{aligned}$ Urban Research}


Table 9: Accessing public wi-fi by location

\begin{tabular}{|lcc|}
\hline Location & $n$ & $\%$ \\
\hline Cafe / Restaurant / Fast food outlet & 376 & $31.3 \%$ \\
\hline Shopping centre & 349 & $29.1 \%$ \\
\hline Hotel / motel & 315 & $26.3 \%$ \\
\hline Airport & 271 & $22.6 \%$ \\
\hline Public space (e.g. park or city square) & 207 & $17.3 \%$ \\
\hline Retail store & 196 & $16.3 \%$ \\
\hline Free Telstra wi-fi & 189 & $15.8 \%$ \\
\hline Public Library & 154 & $12.8 \%$ \\
\hline Public transport & 142 & $11.8 \%$ \\
\hline Other service business & 98 & $8.2 \%$ \\
\hline Sports ground & 81 & $6.8 \%$ \\
\hline Somewhere else & 34 & $2.8 \%$ \\
\hline Used public wi-fi & & \\
\hline Did not use public wi-fi & 677 & $56.4 \%$ \\
\hline Total & & \\
\hline
\end{tabular}

Base: All respondents (n: 1,200)

Table 10: Public wi-fi access by device type

\begin{tabular}{lcc} 
Device & $n$ & $\%$ \\
\hline Mobile phone & 545 & $80.5 \%$ \\
\hline Tablet & 158 & $23.3 \%$ \\
\hline Laptop & 156 & $23.0 \%$ \\
\hline Handheld gaming device & 12 & $1.8 \%$ \\
Other & 9 & $1.3 \%$ \\
\hline Total public wi-fi users & 677 & $100.00 \%$
\end{tabular}

Base: Public wi-fi users (n: 677)
Table 12 ranks the twelve activity types on the basis of the percentage of public wi-fi users that had undertaken them. The most common activity was general internet browsing,

undertaken by three quarters of public wi-fi users. Social networking, email and instant forms of messaging were also popular. One in five public wi-fi users conducted internet banking over such networks, while one in ten paid for goods or services using a credit card and a similar proportion paid for goods and services using Paypal.

Financial Security Risk

More than a quarter of public wi-fi users had conducted financial transactions (internet banking, credit card and Paypal payments) on public wi-fi networks in the previous three months (Table 13: Public wi-fi users conducting financial transactions on public wi-fi networks).

Some people conducting financial transactions indicated that when using public wi-fi they generally took specific online security precautions (such as using a Virtual Private Network [VPN] or DNS Proxy, and/or ensuring that sites/services used operated under HTTPS or SSL). Table 13 reveals that when this group is extracted, $17.7 \%$ of public wi-fi users were exposed to significant risk.

Figure 12: Frequency of public wi-fi use by age

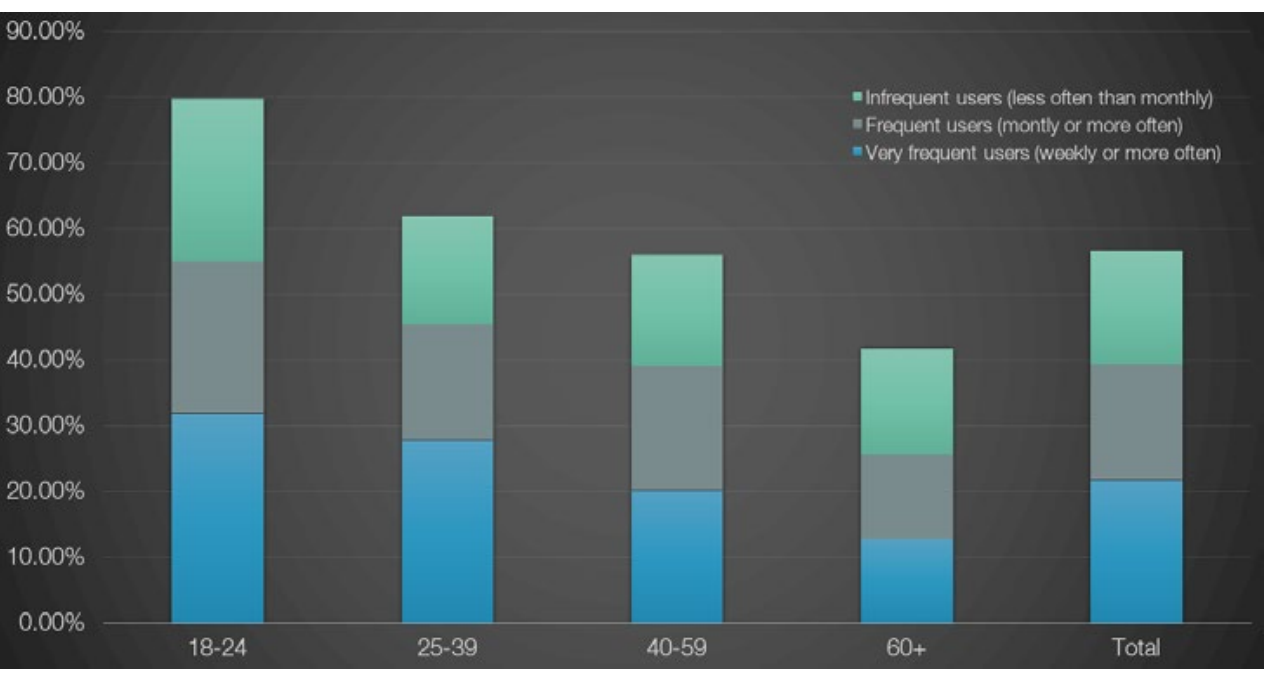

Base: All respondents (n: 1,200) 
Table 11: Public wi-fi access device by age

\begin{tabular}{lccccc} 
Device & $18-24$ & $25-39$ & $40-59$ & $60+$ & Total \\
Mobile phone & $87.2 \%$ & $85.4 \%$ & $78.9 \%$ & $70.3 \%$ & $80.5 \%$ \\
\hline Tablet & $16.3 \%$ & $24.3 \%$ & $23.2 \%$ & $27.1 \%$ & $23.3 \%$ \\
\hline Laptop & $32.6 \%$ & $21.7 \%$ & $19.9 \%$ & $25.4 \%$ & $23.0 \%$ \\
Handheld gaming device & $1.2 \%$ & $4.0 \%$ & $0.4 \%$ & $0.8 \%$ & $1.8 \%$ \\
Other & $3.5 \%$ & $0.9 \%$ & $0.8 \%$ & $2.5 \%$ & $1.5 \%$ \\
& & & & & \\
$\begin{array}{l}\text { Av. number of devices used to } \\
\text { access public wi-fi }\end{array}$ & 1.41 & 1.38 & 1.25 & 1.25 & 1.31
\end{tabular}

Base: Public wi-fi users (n: 677)

Figure 13: Number of devices used to access public wi-fi by age

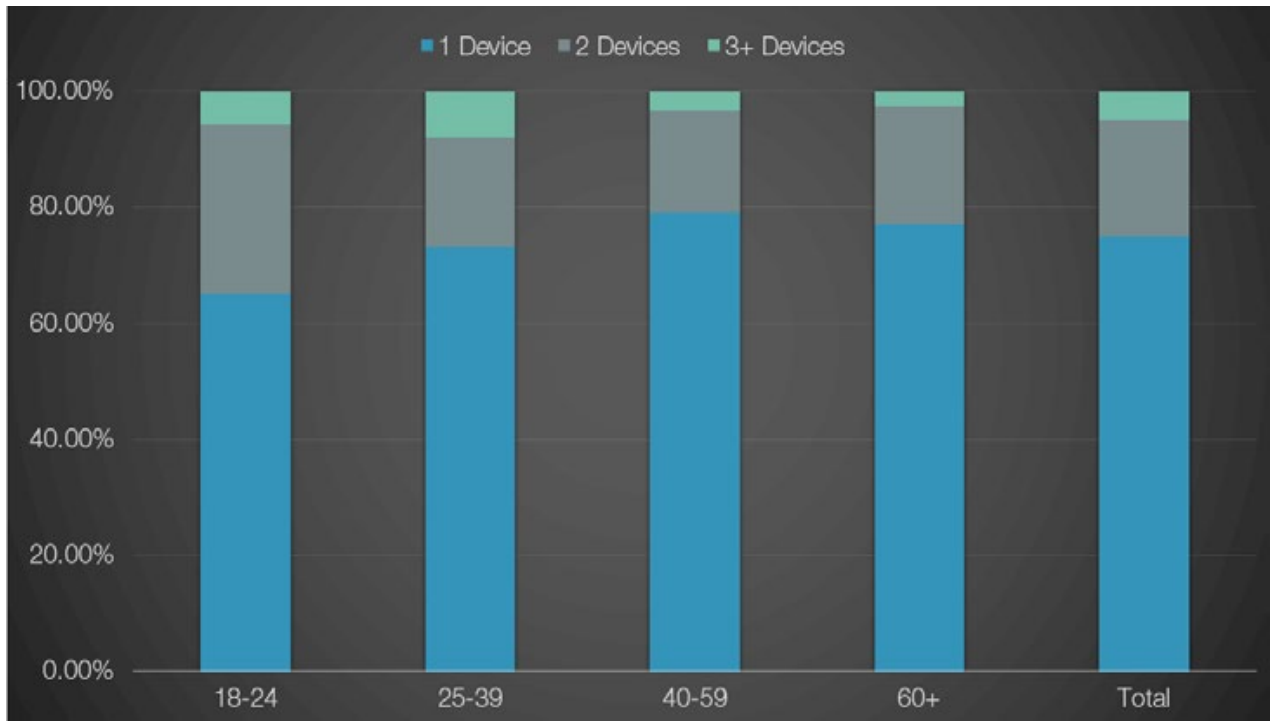

More than one third of public wi-fi users aged 25-39 had accessed financial services on public wi-fi networks and just under one in four had done so without taking any specific online security precautions (Figure 13)

Interestingly, young people who had undertaken financial transactions on public wi-fi networks were less likely to employ specific security measures than older users (although the small size of the sample means that this result should be treated with some caution).

Work Services Security Risk

One in five public wi-fi users had logged into work services, including email and file sharing systems in the previous three months, although one third of such users did so with some specific online security protection in place (Table 12; Figure 14). As such, $14 \%$ of public wi-fi users had logged into work services on public wi-fi networks without any specific security.

Table 12: Online activities conducted on public wi-fi networks in previous 3 months

\begin{tabular}{|lcc|}
\hline Activity & $n$ & $\%$ \\
\hline 1. General internet browsing & 523 & $77.3 \%$ \\
\hline 2. Social networking (i.e. Facebook / Twitter) & 388 & $57.3 \%$ \\
\hline 3. Sending or receiving personal emails & 344 & $50.8 \%$ \\
\hline 4. Chat or instant messaging (e.g. Texting, Snapchat) & 289 & $42.7 \%$ \\
\hline 5. Internet banking & 150 & $22.2 \%$ \\
\hline 6. Using work services (e.g. work email / file sharing) & 146 & $21.6 \%$ \\
\hline 7. Downloading or uploading documents & 127 & $18.8 \%$ \\
\hline 8. Streaming audio / video (e.g. live sport / Spotify) & 92 & $13.6 \%$ \\
\hline 9. Downloading or uploading audio or video files & 88 & $13.0 \%$ \\
\hline 10. Paying for goods or services using a credit card & 80 & $11.8 \%$ \\
\hline 11. Skype/FaceTime/Other VOIP & 77 & $11.4 \%$ \\
\hline 12. Paying for goods or services using Paypal & 68 & $10.0 \%$ \\
\hline Total accessing public wi-fi & $\mathbf{6 7 7}$ & $\mathbf{1 0 0 . 0} \%$
\end{tabular}

\section{RMIT $\mid \begin{aligned} & \text { Centre for } \\ & \text { UNIVRSSTYY }\end{aligned}$}


More than one quarter of users aged 25-39 had used public wi-fi to connect to work services, although many indicated that when using public wi-fi they deployed specific security measures.

Younger and older users were less likely use work services, as might be expected in terms of workforce participation rates for these age groups. However, of the small percentage of younger users that did access work services, few did so with any specific online security protection.

Wi-fi or mobile data?

Public wi-fi users were asked whether there were times they chose not to use a public wi-fi network despite its availability. Almost one in five of those that had accessed public wi-fi in the past three months could be described 'committed' users-always choosing to use public wi-fi when it is available (Figure 15). Two thirds of users sometimes decided against using public wi-fi.

When asked why they chose not to use public wi-fi despite its availability, just over one third of respondents simply noted that they did not require network access at the time (Table 14). One in five respondents chose not to use a public wi-fi network on the grounds of security concerns. Some of those with security concerns indicated that particular networks seemed less secure, others made their security decisions on the grounds of the type of activities they wanted to conduct online (see selected comments - Figure 17; and analysis of network preferences for selected online activities - Table 15).

Other common reasons that public wi-fi users decided against using a network at a particular time included concerns about speed and quality of service of the available network and the inconvenience of the login/connection process. One in ten indicated a preference for using their own mobile data - with some of these respondents clearly using public wi-fi when they run out of mobile data credit.
Table 13: Public wi-fi users conducting financial transactions on public wi-fi networks

\begin{tabular}{lcc} 
Transactions & $n$ & $\%$ \\
Conducted financial transactions & 179 & $26.4 \%$ \\
$\begin{array}{l}\text { Conducted financial transactions without taking } \\
\text { any specific security measures* }\end{array}$ & 120 & $17.7 \%$ \\
\hline Total public wi-fi users & 677 & $100.0 \%$
\end{tabular}

Base: Public wi-fi users (n: 677)

"using a Virtual Private Network NPNN] or DNS Proxy, and/or ensuring that sites/services used operated under HTTPS or SSL

Figure 14: Percentage of public wi-fi users conducting financial transactions on public wi-fi networks by age

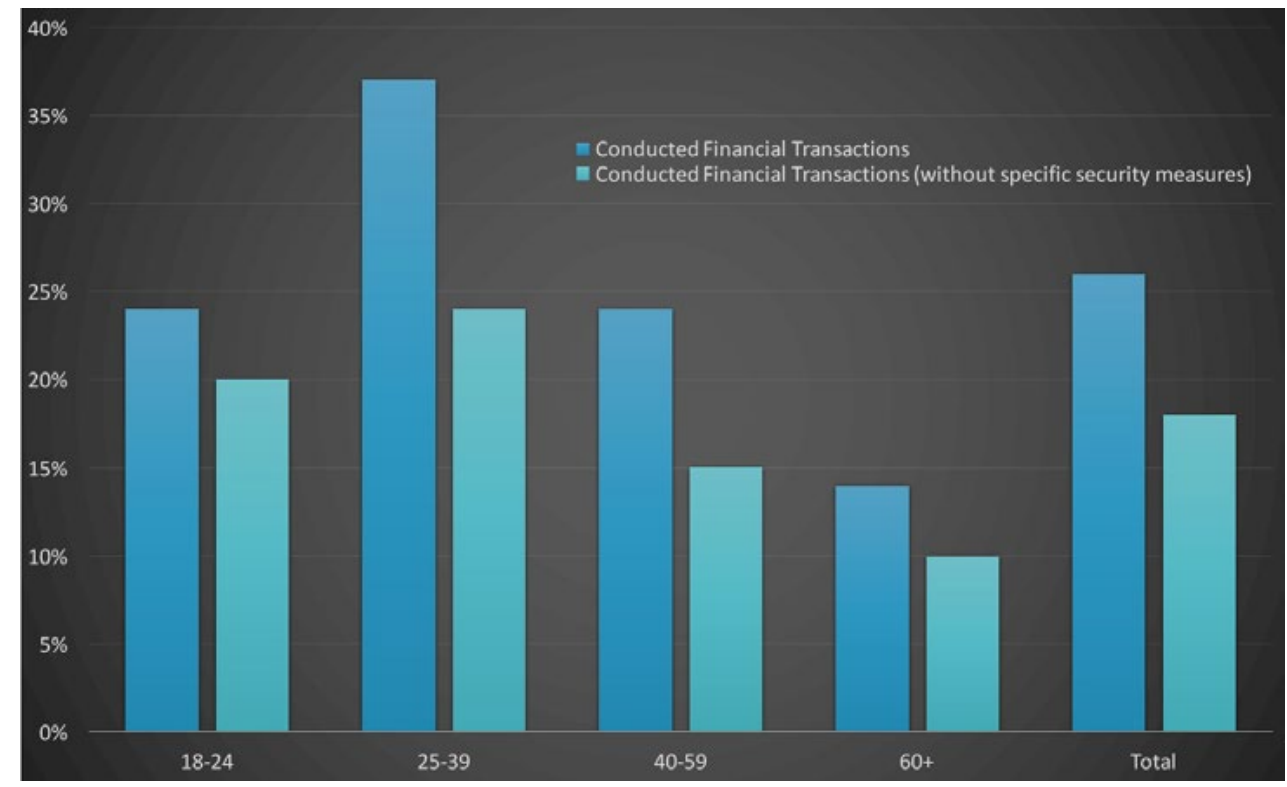

Base: Public wi-fi users (n: 677) 
Figure 15: Percentage of public wi-fi users accessing work services on public wi-fi networks by age

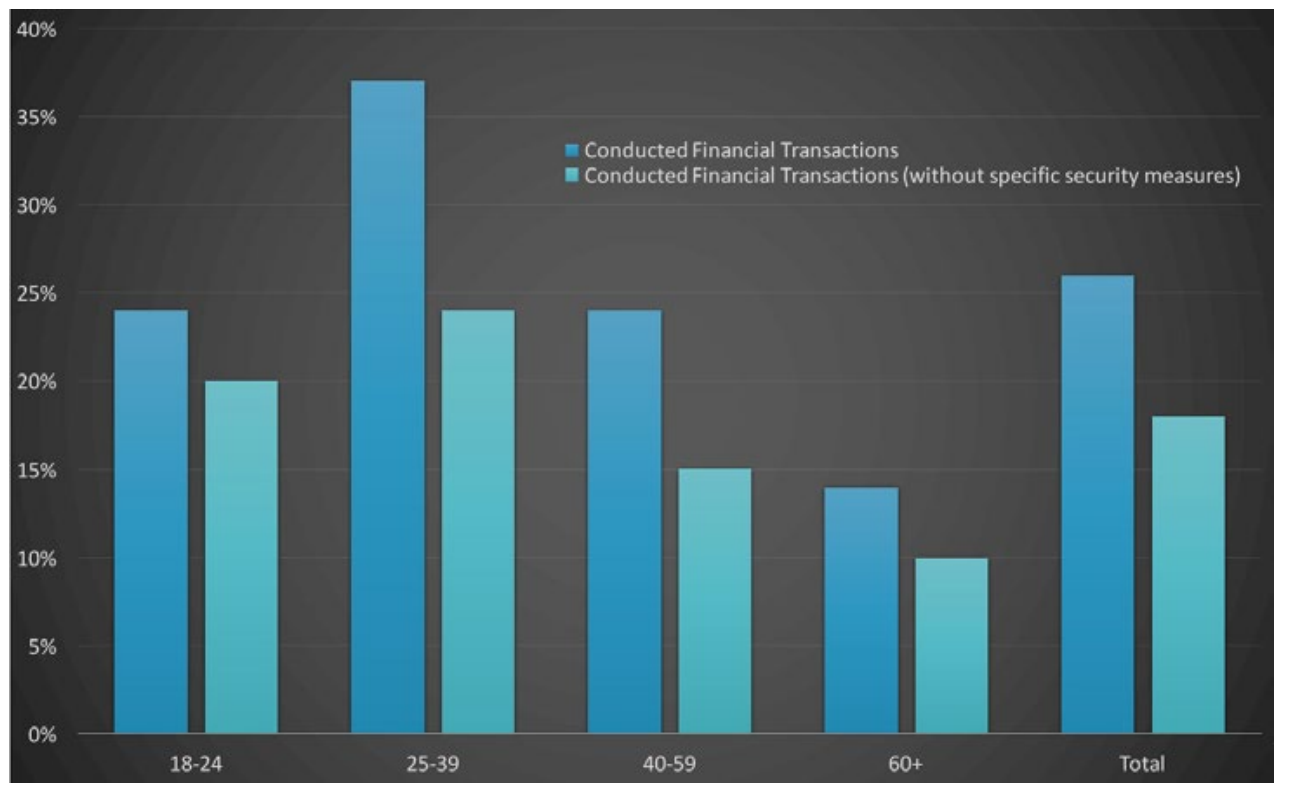

Base: Public wi-fi users (n: 677)

Respondents were asked to indicate their wireless network access preference for conducting a range of online activities in circumstances where public wi-fi and cellular networks were available. Table 15 presents preference data amongst those that indicated they would undertake selected online activities on wireless networks.

Overall, the data reveal a degree of ambivalence with regards to the network used to undertake many online activities. However, consumers did prefer to use public wi-fi for high data-use activities, including downloading or uploading audio or video files and streaming audio/video. The data also revealed that more than two in three people who conduct wireless online financial transactions prefer to use cellular networks for these tasks. Still, 10\% respondents who conduct wireless online financial transactions indicated a preference for
Figure 16: Public wi-fi users - network choices

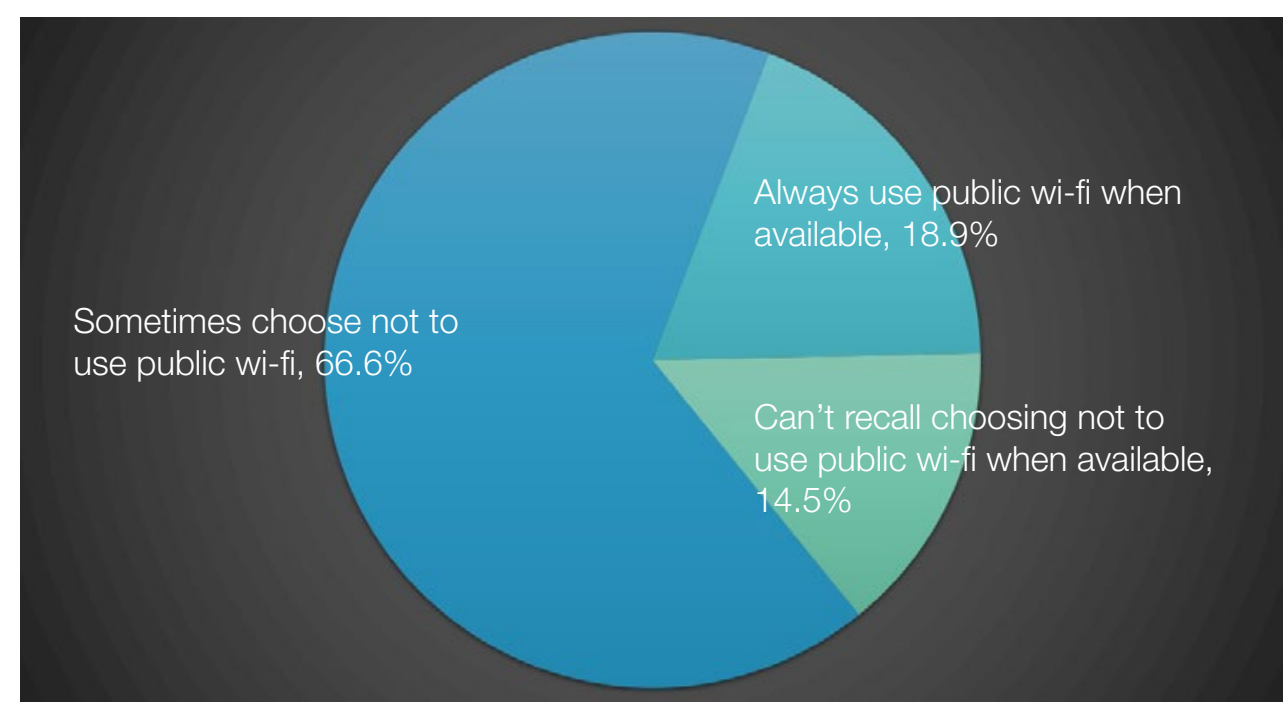

Base: Public wi-fi users (n: 677)

using public wi-fi and a further $20 \%$ have no preferred network and therefore are seemingly unclear about the security deficiencies of public wi-fi.

\section{Public wi-fi security}

Perceptions of security

Respondents were asked how secure they thought public wi-fi networks were in terms of protecting private information. Almost two thirds of respondents indicated that they thought public wi-fi was an insecure form of connectivity. In contrast, just $23 \%$ of respondents were confident that public wi-fi was secure (Figure 18).

As might be expected, non-users were less sure of the security of public wi-fi (Table 16). They were cautious about the security capacity of public networks, with just $16 \%$ of non-users

\section{RMIT $\mid \begin{aligned} & \text { Centre for } \\ & \text { UNIVRSSTYY }\end{aligned}$}




\section{Security concerns}

- Don't always trust the free networks

- Didn't seem safe

- $\quad$... did not feel safe using their wi-fi for what I was wanting to do...

- Worried about security (e.g. wouldn't use a public network for internet banking, but would use it for a Skype call)

- Security of my information over a public network.

- Not secured or encrypted. Only use public wi-fi for general browsing or lookup, no personal details.

- ... I have enough data without needing to risk giving away personal details.

- .... worry about privacy and security.

Speed/Quality of service

- I only choose to use networks I know to be fast and reliable - most free networks are ridiculously slow so I use my phone's mobile data instead.

- Public wi-fi is generally slower than the internet my phone already has (4g) I only connect to public wi-fi when my data is low and I need to use the internet for something.

Preferred to use mobile data

- I had lots of data left on my phone.

- I had enough of my own [mobile data] to last me

- I wasn't using large volumes of data and it would have been more effort to use the wi-fi.

- I have a huge data allowance and would rather use my personal internet whenever possible, rather than public wi-fi.

- I've already got plenty of mobile internet on my phone, I never use it up. I would only use a public network if I was close to running out, or if my third child (who is two) got a bit out of control and I felt the need to show him the Octonauts or something on YouTube to get him back to normal.

Login requirements

- Sometimes it's a hassle to login and if I have data left it's just easier to use that for small traffic, ie. Emails.

- There were too many steps to access wi-fi (entering email, name and address details) and I thought it was just an information gathering tool.

- The wi-fi network had an overwhelming number of pages relating to legal disclaimers and special terms and conditions. After scrolling through it all I just gave up and could not be bothered signing up.

- Because you had to sign up and give your email to get access and I didn't want spam emails after that.

Usage restrictions

- Very small data allowance.

- It wouldn't allow me access to some apps. 
suggesting that public wi-fi was either fairly or very secure compared to users, amongst whom $27 \%$ were confident that wi-fi was secure.

\section{Password protection}

The majority of respondents were confident that signing into public wi-fi using a password was important for the security of private information (Figure 19). Four in five users felt passwordprotected networks provided greater security than those without (Table 17). Unfortunately, this is a misjudged confidence. As we discuss above, public wi-fi security may be compromised even when legitimate password protection is in place, and the illusion of password protection is a commonly deployed feature of wi-fi attacks.

\section{Public wi-fi protection tools - awareness}

Respondents were asked to indicate whether any of the 'tools' listed in Table 19 would help protect their private information when using a public wi-fi network.

While approximately half of all respondents felt they understood the value (or lack of value) of utilising a firewall and anti-virus software to enhance security on public wi-fi networks, less

Table 14: Reason public wi-fi users decided not to use a network on at least one occasion in past three months: comment summary

\begin{tabular}{lcc} 
Reason & $n$ & $\%$ \\
\hline Network access not required & 174 & $38.6 \%$ \\
\hline Security concerns & 105 & $23.3 \%$ \\
\hline Speed/Quality of service & 76 & $16.9 \%$ \\
\hline Preferred to use mobile data & 55 & $12.2 \%$ \\
\hline Login requirements & 44 & $9.8 \%$ \\
Usage restrictions & 5 & $1.1 \%$ \\
NA & 17 & $3.8 \%$ \\
Total $^{*}$ & $\mathbf{4 5 1}$ & $\mathbf{1 0 0 . 0} \%$
\end{tabular}

*Public wi-fi users choosing not to use a specific network at some point in the past 3 months.
Table 15: Wireless access preferences - selected online activities

\begin{tabular}{|c|c|c|c|c|c|c|c|}
\hline & \multicolumn{2}{|c|}{$\begin{array}{c}\text { Prefer } \\
\text { public wi-fi }\end{array}$} & \multicolumn{2}{|c|}{$\begin{array}{l}\text { Have no } \\
\text { preference }\end{array}$} & \multicolumn{2}{|c|}{$\begin{array}{c}\text { Prefer } \\
\text { mobile data }\end{array}$} & \multirow[t]{2}{*}{ Total* $^{*}$} \\
\hline & $\mathrm{n}$ & $\%$ & $\mathrm{n}$ & $\%$ & $\mathrm{n}$ & $\%$ & \\
\hline General internet browsing & 420 & $40.3 \%$ & 340 & $32.6 \%$ & 283 & $27.1 \%$ & 1043 \\
\hline $\begin{array}{l}\text { Social networking (i.e. Facebook/ } \\
\text { Twitter) }\end{array}$ & 293 & $33.3 \%$ & 287 & $32.6 \%$ & 301 & $34.2 \%$ & 881 \\
\hline $\begin{array}{l}\text { Chat or instant messaging (e.g. } \\
\text { Texting, Snapchat) }\end{array}$ & 257 & $28.6 \%$ & 297 & $33.0 \%$ & 345 & $38.4 \%$ & 899 \\
\hline $\begin{array}{l}\text { Downloading or uploading } \\
\text { documents }\end{array}$ & 232 & $28.6 \%$ & 240 & $29.6 \%$ & 339 & $41.8 \%$ & 811 \\
\hline $\begin{array}{l}\text { Downloading or uploading audio } \\
\text { or video files }\end{array}$ & 302 & $40.0 \%$ & 218 & $28.9 \%$ & 235 & $31.1 \%$ & 755 \\
\hline $\begin{array}{l}\text { Streaming audio / video (e.g. live } \\
\text { sport/Spotify) }\end{array}$ & 314 & $44.5 \%$ & 224 & $31.8 \%$ & 167 & $23.7 \%$ & 705 \\
\hline Skype/FaceTime/Other VOIP & 243 & $34.5 \%$ & 234 & $33.2 \%$ & 228 & $32.3 \%$ & 705 \\
\hline $\begin{array}{l}\text { Sending or receiving personal } \\
\text { emails }\end{array}$ & 219 & $22.5 \%$ & 286 & $29.4 \%$ & 469 & $48.2 \%$ & 974 \\
\hline $\begin{array}{l}\text { Using work services (e.g. work } \\
\text { email/file sharing) }\end{array}$ & 160 & $23.1 \%$ & 219 & $31.6 \%$ & 313 & $45.2 \%$ & 692 \\
\hline Internet banking & 83 & $10.4 \%$ & 143 & $17.9 \%$ & 571 & $71.6 \%$ & 797 \\
\hline $\begin{array}{l}\text { Paying for goods or services } \\
\text { using Paypal }\end{array}$ & 85 & $11.4 \%$ & 167 & $22.3 \%$ & 496 & $66.3 \%$ & 748 \\
\hline $\begin{array}{l}\text { Paying for goods or services } \\
\text { using a credit card }\end{array}$ & 81 & $10.9 \%$ & 149 & $20.0 \%$ & 514 & $69.1 \%$ & 744 \\
\hline
\end{tabular}

Base: *Respondents who would undertake selected online activities

than one in three respondents had a definite opinion on the utility of more targeted online security tools.

Public wi-fi users tend to have more definite opinions on the value that more targeted online tools have in enhancing security when using wi-fi (Table 19). Approximately one in three public wi-fi users consider a VPN could enhance security, while one in four identified HTTPS as an important security measure.

\section{DRMIT $\mid \begin{aligned} & \text { Centre for } \\ & \text { UNvivessir } \\ & \text { Urban Research }\end{aligned}$}


Figure 18: Perceptions of public wi-fi security

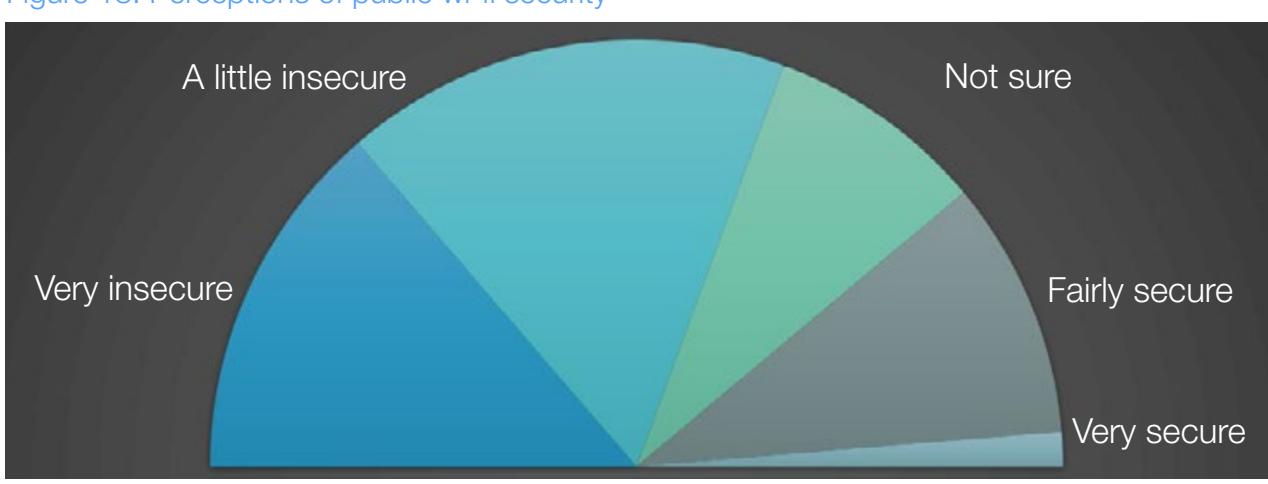

Base: All respondents with a mobile device ( $n: 1179)$

Table 16: Perceptions of public wi-fi security - users and non-users

\begin{tabular}{lcccccc} 
& \multicolumn{2}{c}{ Public wi-fi users } & $\begin{array}{c}\text { Non-users: public } \\
\text { wi-fi }\end{array}$ & \multicolumn{2}{c|}{ All respondents } \\
Very insecure & 138 & $20.4 \%$ & 184 & $36.7 \%$ & 322 & $27.3 \%$ \\
\hline A little insecure & 277 & $40.9 \%$ & 122 & $24.4 \%$ & 399 & $33.9 \%$ \\
\hline Not sure & 81 & $12.0 \%$ & 115 & $23.0 \%$ & 196 & $16.6 \%$ \\
Fairly secure & 158 & $23.3 \%$ & 72 & $14.4 \%$ & 230 & $19.5 \%$ \\
\hline Very secure & 23 & $3.4 \%$ & 8 & $1.6 \%$ & 31 & $2.6 \%$ \\
Total & $\mathbf{6 7 7}$ & $\mathbf{1 0 0 . 0 \%}$ & $\mathbf{5 0 1}$ & $\mathbf{1 0 0 . 0} \%$ & $\mathbf{1 1 7 9}$ & $\mathbf{1 0 0 . 0 \%}$ \\
\hline
\end{tabular}

Base: All respondents with mobile devices (1179)

Table 17: Perceptions of importance of passwords for security on public wi-fi- users and non-users

\begin{tabular}{lcccccc|} 
& \multicolumn{2}{c}{ Public wi-fi users } & $\begin{array}{c}\text { Non-users: public } \\
\text { wi-fi }\end{array}$ & \multicolumn{2}{c|}{ All respondents } \\
Very important & 350 & $52 \%$ & 368 & $73 \%$ & 718 & $61 \%$ \\
\hline Fairly important & 210 & $31 \%$ & 72 & $14 \%$ & 282 & $24 \%$ \\
\hline Not important & 61 & $9 \%$ & 13 & $3 \%$ & 74 & $6 \%$ \\
Not sure & 56 & $8 \%$ & 49 & $10 \%$ & 105 & $9 \%$ \\
\hline Total & $\mathbf{6 7 7}$ & $\mathbf{1 0 0 . 0} \%$ & $\mathbf{5 0 2}$ & $\mathbf{1 0 0 . 0} \%$ & $\mathbf{1 1 7 9}$ & $\mathbf{1 0 0 . 0 \%}$
\end{tabular}

Base: All respondents with mobile devices (1179)
Figure 19: Perceptions of importance of passwords for security on public wi-fi

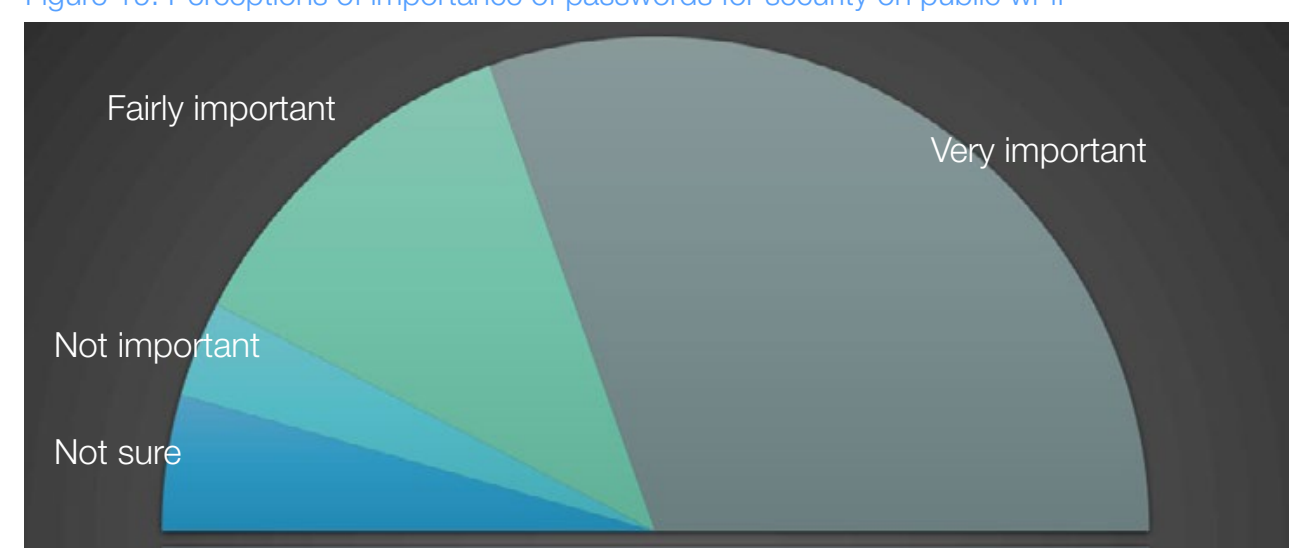

Base: All respondents with a mobile device (n: 1179)

Public wi-fi protection tools - use

Public wi-fi users were asked whether they deployed any of the digital tools outlined in Table 19 to specifically enhance their public wi-fi security. While the two general tools (Anti-virus and Firewall) were used by a quarter of public wi-fi users, more specialist tools, such as VPNs, were used as a security tool by only one in ten public wi-fi users (Table 20).

Table 18: Respondent awareness of the utility of selected digital tools for enhancing security when using public wi-fi

\begin{tabular}{lccc} 
& Yes & No & Not sure \\
\hline Firewall & $42.0 \%$ & $8.6 \%$ & $49.4 \%$ \\
\hline Anti-virus & $34.7 \%$ & $14.3 \%$ & $51.1 \%$ \\
VPN & $26.9 \%$ & $7.5 \%$ & $65.6 \%$ \\
\hline HTTPS & $20.7 \%$ & $9.0 \%$ & $70.4 \%$ \\
\hline SSL & $15.4 \%$ & $8.6 \%$ & $76.0 \%$ \\
\hline DNS Proxy & $10.4 \%$ & $10.0 \%$ & $79.6 \%$
\end{tabular}

Base: All respondents with mobile devices (1179) 
Table 19: Public wi-fi user awareness of the utility of selected digital tools for enhancing security when using public wi-fi

\begin{tabular}{lccc} 
Total & Yes & No & Not sure \\
\hline Firewall & $47.3 \%$ & $8.9 \%$ & $43.9 \%$ \\
\hline Anti-virus & $39.3 \%$ & $13.9 \%$ & $47.0 \%$ \\
\hline VPN & $32.5 \%$ & $9.3 \%$ & $58.2 \%$ \\
HTTPS & $24.4 \%$ & $10.3 \%$ & $65.4 \%$ \\
\hline SSL & $18.2 \%$ & $10.3 \%$ & $71.6 \%$ \\
DNS Proxy & $14.0 \%$ & $10.2 \%$ & $75.8 \%$
\end{tabular}

Base: Public wi-fi users (677)

Table 20: Use of digital tools to enhance online security: Public wi-fi users

\begin{tabular}{lcc} 
& $n$ & $\%$ \\
Anti-virus & 163 & $24.1 \%$ \\
\hline Firewall & 160 & $23.6 \%$ \\
\hline HTTPS & 91 & $13.4 \%$ \\
VPN & 72 & $10.6 \%$ \\
SSL & 56 & $8.3 \%$ \\
DNS Proxy & 45 & $6.6 \%$ \\
\hline Total & $\mathbf{6 7 7}$ & $\mathbf{1 0 0 . 0} \%$
\end{tabular}

Base: Public wi-fi users (n: 677) 


\section{Conclusion:}

Implications for policy-makers, network providers and consumers

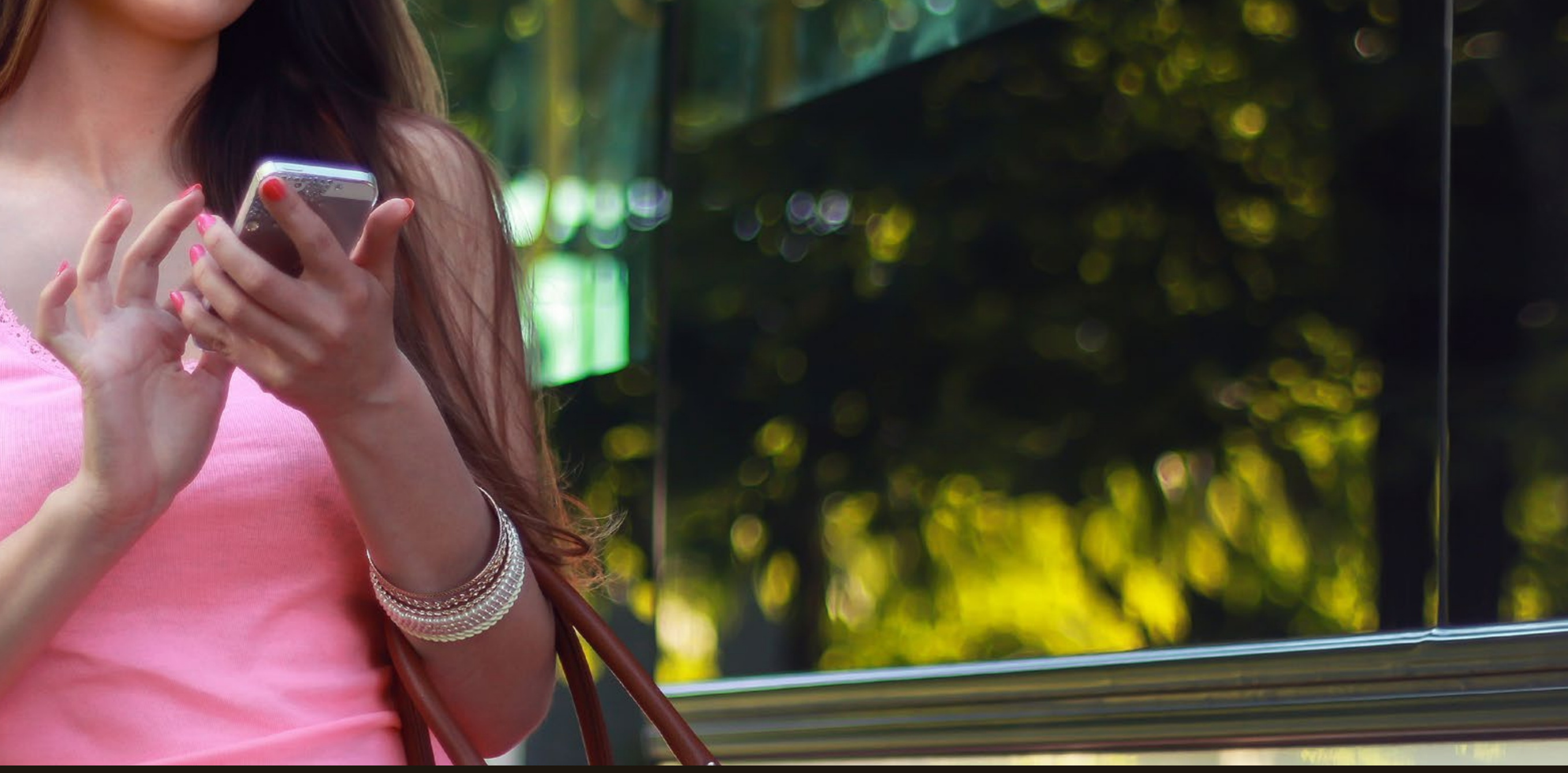


Public wi-fi provision and use in Australia has grown significantly in the past five years Survey data in this report suggest that over half the Australian population used a public wi-fi network in the three months before the survey was undertaken. Four in five people aged 18-24 years accessed a public wi-fi network in that period

The security risks for users of public wi-fi networks in Australia are similar to those experienced across the globe. However, recent data showing that Australia ranks sixth highest on an international scale of attacks on web applications suggests that the internet community - that is, all sectors of Australian society with an on-line presence - should be highly attentive to security issues. ${ }^{43}$

The accessibility of public wi-fi networks requires particular attention to data security. While the compromise of personal privacy is a pervasive issue when security is breached, this survey highlights two specific risks:

- almost one in five users of public wi-fi were exposed to significant risk in conducting financial transactions without taking any security precautions

- $\quad$ one in seven public wi-fi users undertakes work-related activities on unsecured wi-fi networks, exposing business, governmental and civil society organisations to significant risk.

The survey data show a generally low awareness of security measures available for public wi-fi networks. Almost three quarters of survey respondents, for example, were unsure of whether the increasingly common httpss:// standard was a useful security measure. Even where users were familiar with security options, the survey data show that some chose to forgo security measures and conduct sensitive activities on unsecured networks. In summary, the survey suggests that a proportion of public wi-fi users choose convenience over security.

However, the limited literature in the area of public wi-fi consumer behaviour, cited in this

43. Akamai: State of the Internet 2016/2 https://www.akamai.com/us/en/multimedia/documents/state-of-the-internet/ akamai-q2-2016-state-of-the-internet-security-report.pd report, also suggests that consumers are willing to change practices if security threats are clearly understood

Public wi-fi networks are increasingly integrated with mobile cellular services, and network security is a challenge shared by policymakers, the communications industry and consumers. As we have seen, mobile phone manufacturers and software developers are responding to security issues with new tools at device and internet browser level. This report also outlines actions and information resources that can further assist.

However, we suggest there is a need for three system-level responses to enhance the secure provision and use of public wi-fi:

1. Australian government communication authorities should clarify licensing requirements and responsibilities that engage public wi-fi network providers. Uncertainty in this area becomes increasingly problematic as wi-fi networks multiply and are further integrated with regulated mobile cellular services through seamless handover mechanisms.

2. Public wi-fi network providers should adopt an 'educate first' stance in their information and terms and conditions. Some terms and conditions governing public wi-fi are in dire need of revision to a friendlier and more user-oriented format. The current defensive, corporate risk-focussed posture of many T\&Cs has little educative value, and ultimately brings into question the rationale for providing a public network.

3. Governmental, industry and consumer bodies in this field should consider development of a public awareness campaign on public wi-fi security. Australian governments, in particular, are international innovators in public awareness campaigns, in areas such as health, physical activity, road safety and so on. The peer-reviewed academic literature points to the effectiveness of well-targetted public awareness campaigns, particularly in achieving broad issue awareness and influencing risk behavour. ${ }^{44}$

44. Cavill, N. \& Bauman, A. 'Changing the way people think about health-enhancing physical activity: do mass media campaigns have a role?', Journal of Sports Sciences, 22(8): 771-790, 2014; Rundmo, T. \& Iversen, H. 'Risk perception and driving behaviour among adolescents in two Norwegian countries before and after a traffic safety campaign', Safety Science, 42(2): 1-21, 2004 
6. Appendices 


\begin{tabular}{|l|r|c|}
\hline \multicolumn{3}{|c|}{ Households (number of people aged $\mathbf{1 8}$ and over) } \\
\hline & \multicolumn{1}{c|}{$\mathbf{n}$} & \multicolumn{1}{c|}{$\%$} \\
\hline 1 person & 253 & $21.1 \%$ \\
\hline 2 people & 680 & $56.7 \%$ \\
\hline 3 people & 164 & $13.7 \%$ \\
\hline 4 people & 79 & $6.6 \%$ \\
\hline 5 people & 15 & $1.3 \%$ \\
\hline 6 people & 7 & $0.6 \%$ \\
\hline 7 people & - & $0.0 \%$ \\
\hline 8 people & 1 & $0.1 \%$ \\
\hline 9 people & 2 & $0.2 \%$ \\
\hline Total & 1,200 & $100.0 \%$ \\
\hline
\end{tabular}

\begin{tabular}{|l|r|c|}
\hline \multicolumn{3}{|c|}{ Gender } \\
\hline & \multicolumn{1}{c|}{ n } & \multicolumn{1}{c|}{$\%$} \\
\hline Male & 591 & $49.3 \%$ \\
\hline Female & 609 & $50.8 \%$ \\
\hline Total & 1,200 & $100.0 \%$ \\
\hline
\end{tabular}

\begin{tabular}{|l|r|c|}
\hline \multicolumn{3}{|c|}{ Age (Grouped) } \\
\hline & \multicolumn{1}{|c|}{$\mathbf{n}$} & \multicolumn{1}{c|}{$\%$} \\
\hline $18-24$ & 109 & $9.1 \%$ \\
\hline $25-39$ & 367 & $30.6 \%$ \\
\hline $40-59$ & 441 & $36.8 \%$ \\
\hline $60+$ & 282 & $23.5 \%$ \\
\hline Total & 1,200 & $100.0 \%$ \\
\hline
\end{tabular}

\begin{tabular}{|c|c|c|}
\hline \multicolumn{3}{|c|}{ Age } \\
\hline & $\mathrm{n}$ & $\%$ \\
\hline $18-24$ & 109 & $9.1 \%$ \\
\hline $25-29$ & 121 & $10.1 \%$ \\
\hline $30-34$ & 143 & $11.9 \%$ \\
\hline $35-39$ & 103 & $8.6 \%$ \\
\hline $40-44$ & 107 & $8.9 \%$ \\
\hline $45-49$ & 112 & $9.3 \%$ \\
\hline $50-54$ & 108 & $9.0 \%$ \\
\hline $55-59$ & 113 & $9.4 \%$ \\
\hline $60-64$ & 98 & $8.2 \%$ \\
\hline $65-69$ & 82 & $6.8 \%$ \\
\hline $70+$ & 103 & $8.6 \%$ \\
\hline Total & 1,200 & $100.0 \%$ \\
\hline
\end{tabular}

\begin{tabular}{|l|r|c|}
\hline \multicolumn{3}{|c|}{ Households (number of people aged 14-17 years) } \\
\hline & \multicolumn{1}{c|}{$\mathbf{n}$} & \multicolumn{1}{c|}{$\%$} \\
\hline None & 1,100 & $91.7 \%$ \\
\hline 1 person & 77 & $6.4 \%$ \\
\hline 2 people & 22 & $1.8 \%$ \\
\hline 3 people & 1 & $0.1 \%$ \\
\hline Total & 1,200 & $100.0 \%$ \\
\hline
\end{tabular}

\begin{tabular}{|l|r|c|}
\hline \multicolumn{3}{|c|}{ Households (number of people aged $\mathbf{1 3}$ years or under) } \\
\hline & $\mathbf{n}$ & $\boldsymbol{\%}$ \\
\hline None & 937 & $78.1 \%$ \\
\hline 1 person & 140 & $11.7 \%$ \\
\hline 2 people & 93 & $7.8 \%$ \\
\hline 3 people & 24 & $2.0 \%$ \\
\hline 4 people & 5 & $0.4 \%$ \\
\hline 5 people & 1 & $0.1 \%$ \\
\hline Total & 1,200 & $100.0 \%$ \\
\hline
\end{tabular}




\begin{tabular}{|l|r|c|}
\hline \multicolumn{3}{|c|}{ Generation } \\
\hline & \multicolumn{1}{|c|}{$\mathbf{n}$} & \multicolumn{1}{|c|}{$\%$} \\
\hline Before 1948 (Pre Boomers) & 148 & $12.3 \%$ \\
\hline Between 1948 and 1964 (Baby Boomers & 346 & $28.8 \%$ \\
\hline Between 1965 and 1979 (Gen X) & 323 & $26.9 \%$ \\
\hline Between 1980 and 1994 (Gen Y) & 347 & $28.9 \%$ \\
\hline In 1995 or after (Gen Z) & 35 & $2.9 \%$ \\
\hline Prefer not to say & 1 & $0.1 \%$ \\
\hline Total & 1,200 & $100.0 \%$ \\
\hline
\end{tabular}

\begin{tabular}{|l|r|c|}
\hline \multicolumn{3}{|c|}{ Country of birth } \\
\hline & \multicolumn{1}{|c|}{$\mathbf{n}$} & \multicolumn{1}{|c|}{$\%$} \\
\hline Australia & 853 & $71.1 \%$ \\
\hline United Kingdom & 110 & $9.2 \%$ \\
\hline USA or Canada & 14 & $1.2 \%$ \\
\hline New Zealand & 32 & $2.7 \%$ \\
\hline Asia & 92 & $7.7 \%$ \\
\hline Europe & 50 & $4.2 \%$ \\
\hline Africa & 16 & $1.3 \%$ \\
\hline The Middle East & 6 & $0.5 \%$ \\
\hline Prefer not to say & 14 & $1.2 \%$ \\
\hline Oceania & 7 & $0.6 \%$ \\
\hline Middle/South America & 6 & $0.5 \%$ \\
\hline Total & 1,200 & $100.0 \%$ \\
\hline
\end{tabular}

\begin{tabular}{|l|r|c|}
\hline \multicolumn{3}{|c|}{ Marital status } \\
\hline & \multicolumn{1}{|c|}{$\mathbf{n}$} & \multicolumn{1}{c|}{$\%$} \\
\hline Single, never married & 280 & $23.3 \%$ \\
\hline A couple with no children & 213 & $17.8 \%$ \\
\hline A couple with children at home & 314 & $26.2 \%$ \\
\hline Single parent with children at home & 46 & $3.8 \%$ \\
\hline A couple whose children have left home & 204 & $17.0 \%$ \\
\hline Widowed/divorced/separated & 128 & $10.7 \%$ \\
\hline Prefer not to say & 15 & $1.3 \%$ \\
\hline Total & 1,200 & $100.0 \%$ \\
\hline
\end{tabular}

\begin{tabular}{|l|r|c|}
\hline \multicolumn{3}{|c|}{ CALD status } \\
\hline & \multicolumn{1}{|c|}{$\mathbf{n}$} & \multicolumn{1}{c|}{$\%$} \\
\hline Yes, Non-English speaking & 198 & $16.5 \%$ \\
\hline Yes, Aboriginal / Torres Straight Island & 15 & $1.3 \%$ \\
\hline No, neither & 988 & $82.3 \%$ \\
\hline Total & 1,200 & $100.0 \%$ \\
\hline
\end{tabular}

\begin{tabular}{|l|r|c|}
\hline \multicolumn{3}{|c|}{ Total number of people in household } \\
\hline & \multicolumn{1}{|c|}{$\mathbf{n}$} & $\%$ \\
\hline 1 person & 220 & $18.3 \%$ \\
\hline 2 people & 463 & $38.6 \%$ \\
\hline 3 people & 247 & $20.6 \%$ \\
\hline 4 people & 178 & $14.8 \%$ \\
\hline 5 people & 59 & $4.9 \%$ \\
\hline 6 people & 26 & $2.2 \%$ \\
\hline 7 people & 2 & $0.2 \%$ \\
\hline 8 people & 2 & $0.2 \%$ \\
\hline 9 people & 2 & $0.2 \%$ \\
\hline Total & 1,200 & $100.0 \%$ \\
\hline
\end{tabular}

\begin{tabular}{|l|r|c|}
\hline \multicolumn{3}{|c|}{ Employment status } \\
\hline & \multicolumn{1}{|c|}{$\mathbf{n}$} & $\%$ \\
\hline Self-employed & 70 & $5.8 \%$ \\
\hline Employed full-time & 463 & $38.6 \%$ \\
\hline Employed part-time & 191 & $15.9 \%$ \\
\hline Engaged in home duties & 76 & $6.3 \%$ \\
\hline Retired on a pension & 173 & $14.4 \%$ \\
\hline A self-funded retiree & 64 & $5.3 \%$ \\
\hline A student & 79 & $6.6 \%$ \\
\hline Not employed at the moment & 67 & $5.6 \%$ \\
\hline Prefer not to say & 16 & $1.3 \%$ \\
\hline Total & 1,200 & $100.0 \%$ \\
\hline
\end{tabular}




\begin{tabular}{|l|r|c|}
\hline \multicolumn{3}{|c|}{ Education level } \\
\hline & \multicolumn{1}{|c|}{$\mathbf{n}$} & \multicolumn{1}{|c|}{$\%$} \\
\hline Secondary schooling incomplete & 101 & $8.4 \%$ \\
\hline Secondary schooling completed & 296 & $24.7 \%$ \\
\hline Trade qualification & 144 & $12.0 \%$ \\
\hline Vocational certificate & 141 & $11.8 \%$ \\
\hline Tertiary education & 492 & $41.0 \%$ \\
\hline Prefer not to say & 26 & $2.2 \%$ \\
\hline Total & 1,200 & $100.0 \%$ \\
\hline
\end{tabular}

\begin{tabular}{|l|r|c|}
\hline \multicolumn{3}{|c|}{ Occupational Group } \\
\hline & \multicolumn{1}{|c|}{$\mathbf{n}$} & $\%$ \\
\hline Unskilled Blue & 45 & $6.2 \%$ \\
\hline Semi-Skilled Blue & 101 & $14.0 \%$ \\
\hline Skilled Blue & 50 & $6.9 \%$ \\
\hline Lower White & 424 & $58.6 \%$ \\
\hline Middle White & 85 & $11.7 \%$ \\
\hline Upper White & 3 & $0.4 \%$ \\
\hline Unemployed & 7 & $1.0 \%$ \\
\hline Refused & 9 & $1.2 \%$ \\
\hline Total & 724 & $100.0 \%$ \\
\hline
\end{tabular}

\begin{tabular}{|l|r|c|}
\hline \multicolumn{3}{|c|}{ Household income } \\
\hline & \multicolumn{1}{|c|}{$\mathbf{n}$} & \multicolumn{1}{|c|}{$\%$} \\
\hline Under $\$ 30,000$ p.a. & 164 & $13.7 \%$ \\
\hline$\$ 30,000$ to $\$ 50,000$ p.a. & 181 & $15.1 \%$ \\
\hline$\$ 50,000$ to $\$ 75,000$ p.a. & 208 & $17.3 \%$ \\
\hline Over $\$ 75,000$ & 433 & $36.1 \%$ \\
\hline Prefer not to say & 147 & $12.3 \%$ \\
\hline Dont know & 66 & $5.5 \%$ \\
\hline Total & 1,200 & $100.0 \%$ \\
\hline
\end{tabular}

\begin{tabular}{|l|r|c|}
\hline \multicolumn{3}{|c|}{ Housing status } \\
\hline & \multicolumn{1}{|c|}{$\mathbf{n}$} & $\%$ \\
\hline Own your own home & 492 & $41.0 \%$ \\
\hline Are you buying it & 199 & $16.6 \%$ \\
\hline Renting it or & 344 & $28.7 \%$ \\
\hline Living with parents/family & 123 & $10.3 \%$ \\
\hline Other & 11 & $0.9 \%$ \\
\hline Prefer not to say & 24 & $2.0 \%$ \\
\hline Caravan & 6 & $0.5 \%$ \\
\hline Total & 1,200 & $100.0 \%$ \\
\hline
\end{tabular}

\begin{tabular}{|l|r|c|}
\hline \multicolumn{3}{|c|}{ State } \\
\hline & \multicolumn{1}{|c|}{$\mathbf{n}$} & $\%$ \\
\hline New South Wales & 409 & $34.1 \%$ \\
\hline Victoria & 316 & $26.3 \%$ \\
\hline Queensland & 249 & $20.8 \%$ \\
\hline South Australia & 94 & $7.8 \%$ \\
\hline West Australia & 132 & $11.0 \%$ \\
\hline Total & 1,200 & $100.0 \%$ \\
\hline
\end{tabular}

\begin{tabular}{|l|r|c|}
\hline \multicolumn{3}{|c|}{ Location } \\
\hline & \multicolumn{1}{|c|}{$\mathbf{n}$} & \multicolumn{1}{c|}{$\%$} \\
\hline A metropolitan location & 783 & $65.3 \%$ \\
\hline A regional location & 332 & $27.7 \%$ \\
\hline A rural location & 85 & $7.1 \%$ \\
\hline Total & 1,200 & $100.0 \%$ \\
\hline
\end{tabular}




\section{Appendix 2: Consumer Survey Instrument}

\section{Study No. 15/04/1486}

Omnibus 27

\section{Section A RMIT:}

Asked of full Australia wide sample

Firstly, some questions about wi-fi.

Mobile phone, tablet and mobile broadband plans offered by telecommunication companies (like Telstra, Optus and Vodafone) allow you to wirelessly access the internet using the $3 \mathrm{G} / 4 \mathrm{G}$ mobile phone network.

Wifi is another wireless internet connection option commonly accessible in homes and sometimes in public settings.

In this section of the survey we refer to home wi-fi and public WiFi.

Home wi-fi is defined as a wi-fi network only accessible in and around your home.

Public wi-fi is defined as any WiFi network made available to the general public (either paid or free) by a business, government or community organisation. It does not include wi-fi made available at your workplace.

Q1 Do you have wi-fi at home?

(Q2) Yes ..................................................... 1

(Q4) No ......................................................... 2

(Q4) Don't know ...........................................

\section{IF 'YES' IN Q1 ASK Q2 AND Q3 OTHERWISE GO TO Q4}

Q2 Is your home wi-fi network secured by a password?

Yes ${ }^{2}$ 
How secure do you think your home wi-fi network is in terms of protecting your private information?

Fery secure

ASK ALL

Which of the following mobile devices, if any, do you have?

Multiple responses

allowed
Q6

Q6

Q5

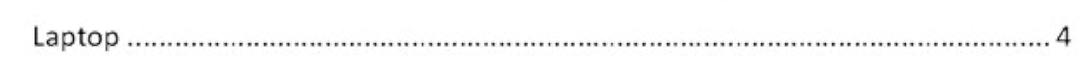

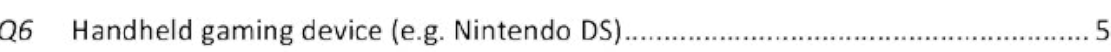

Q6 Other (please specify)

Q6 (Next Section)

\section{IF OWN 'MOBILE BROADBAND DEVICE' (CODE 3 IN Q4) ASK Q5}

Q5 In relation to the mobile broadband device that you have, do you carry this with you to access the internet away from home (rather than using it to access the internet at home only)?

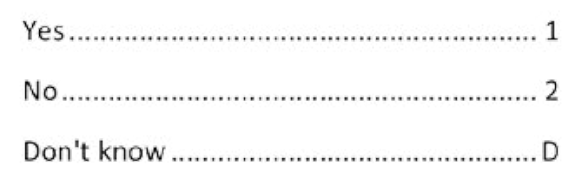

Don't know ................................................

\section{IF OWN DEVICE IN Q4, ASK Q6 \& Q7}

Q6 Mobile phones, Mobile broadband devices and some tablets and laptops wirelessly access the internet using the 3G/4G mobile phone network. Telecommunication companies, such as Telstra, commonly sell customers a monthly data download allowance to access this network.

Please indicate the monthly data allowance for devices you have?

(Note, if you have more than one of each device please indicate your largest data allowance)

\section{DRMIT $\mid \begin{aligned} & \text { Centre for } \\ & \text { UNversir }\end{aligned}$ Urban Research}




\begin{tabular}{|l|c|c|c|c|c|c|c|c|}
\hline & $\begin{array}{c}\text { No } \\
\text { data } \\
\text { allowa } \\
\text { nce }\end{array}$ & $\begin{array}{c}\text { Less } \\
\text { than } \\
\mathbf{5 0 0 m b}\end{array}$ & $\begin{array}{c}\mathbf{5 0 0 M B} \\
\mathbf{9 9 9 M B}\end{array}$ & $\begin{array}{c}\mathbf{1 -} \\
\mathbf{1 . 9 9 G B}\end{array}$ & $\begin{array}{c}\mathbf{2 -} \\
\mathbf{3 . 9 9 G B}\end{array}$ & $\begin{array}{c}\mathbf{4 - 7 . 9 9} \\
\text { GB }\end{array}$ & $\begin{array}{c}\mathbf{8} \text { or } \\
\text { more } \\
\text { GB }\end{array}$ & $\begin{array}{c}\text { Don't } \\
\text { know }\end{array}$ \\
\hline Mobile phone & 1 & 1 & 2 & 3 & 4 & 5 & 6 & $\mathrm{D}$ \\
\hline Tablet & 1 & 1 & 2 & 3 & 4 & 5 & 6 & $\mathrm{D}$ \\
\hline Mobile Broadband & 1 & 1 & 2 & 3 & 4 & 5 & 6 & $\mathrm{D}$ \\
\hline
\end{tabular}

\section{ASK ALL WITH A DEVICE WITH A DATA ALLOWANCE IN Q6}

Q7 In the last three months, which of the following activities did you undertake using a device connected to the 3G/4G mobile phone network? (Rotate order)

\begin{tabular}{|c|c|c|c|}
\hline & Yes & No \\
\hline a) & General internet browsing & 1 & 2 \\
\hline b) & Social networking (i.e. Facebook / Twitter / Instagram) & 1 & 2 \\
\hline c) & Chat or instant messaging (e.g. Texting, Snapchat) & 1 & 2 \\
\hline d) & Downloading or uploading documents & 1 & 2 \\
\hline e) & Downloading or uploading audio or video files & 1 & 2 \\
\hline f) & Streaming audio / video (e.g. live sport / Spotify) & 1 & 2 \\
\hline g) & Skype/FaceTime/Other VOIP & 1 & 2 \\
\hline h) & Sending or receiving personal emails & 1 & 2 \\
\hline i) & Using work services (e.g. work email / file sharing) & 1 & 2 \\
\hline j) & Internet banking & 1 & 2 \\
\hline k) & Paying for goods or services using Paypal & 1 & 2 \\
\hline I) & Paying for goods or services using a credit card & 1 & 2 \\
\hline & Something else (please specify) & 1 & 2 \\
\hline
\end{tabular}




\section{ASK ALL}

Now for some questions about public wi-fi which is defined as any Wi-Fi network made available to the general public (either paid or free) by a business, government or community organisation, but NOT wi-fi made available at your workplace.

Q8 In the last three months, in which of the following locations, have you used a public wi-fi network? (Rotate order)

\begin{tabular}{|c|c|c|c|}
\hline & \\
\hline & & Yes & No \\
\hline a) & Café / Restaurant / Fast food outlet / Bar & 1 & 2 \\
\hline b) & Other service business (e.g hairdresser) & 1 & 2 \\
\hline c) & Hotel / motel & 1 & 2 \\
\hline d) & Airport & 1 & 2 \\
\hline e) & Shopping centre & 1 & 2 \\
\hline f) & Public transport & 1 & 2 \\
\hline g) & Retail store & 1 & 2 \\
\hline h) & Public Library & 1 & 2 \\
\hline i) & Public space (e.g. park or city square) & 1 & 2 \\
\hline j) & Free Telstra wi-fi hotspot & 1 & 2 \\
\hline k) & Sports ground (e.g. Rod Laver Arena tennis centre / MCG) & 1 & 2 \\
\hline & Somewhere else (please specify) & 1 & 2 \\
\hline
\end{tabular}

Q11 Daily ..................................................... 1

Q11 More than once a week ........................... 2

Q11 Weekly...................................................... 3

Q11 Every 2-3 weeks ................................... 4

Q11 Monthly .................................................. 5

\section{DRMIT $\mid \begin{aligned} & \text { Centre for } \\ & \text { UNversir } \\ & \text { Urban Research }\end{aligned}$}


IF DID NOT USE A PUBLIC WI-FI NETWORK IN THE LAST THREE MONTHS (CODE D IN Q9) ASK Q10 (THEN GO TO Q17)

Q10

What was the main reason you have not used public wi-fi in the last 3 months?

IF USED A PUBLIC WI-FI NETWORK IN THE LAST THREE MONTHS (CODE 1-6 IN Q9) ASK Q11-Q16

Q11 With which type of device have you accessed public

wi-fi in the last 3 months?

Multiple responses allowed

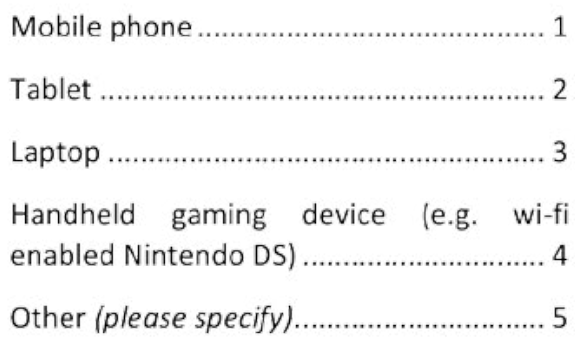

Q12 In the last three months, have you accessed a public wi-fi network that did not require a password to connect?

Yes ….........................................................

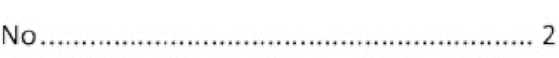

Can't recall ............................................... D

Q13 In the last three months, were there times that you had

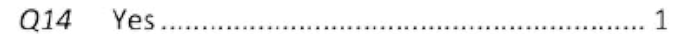

access to a public wi-fi network but chose not to use it?

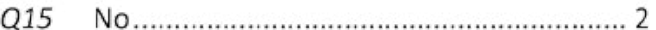

Q15 Can't recall ............................................... D

\section{IF YES IN Q13, ASK Q14, OTHERWISE GO TO Q15}

Q14 What was the main reason you chose not to use the public wi-fi network despite its availability? 
Q15 In the last three months, which of the following activities did you undertake using a public wi-fi network? (Rotate order)

\begin{tabular}{|l|c|c}
\multicolumn{1}{l|}{} & Yes & No \\
\hline a) General internet browsing & 1 & 2 \\
\hline b) Social networking (i.e. Facebook / Twitter / Instagram) & 1 \\
\hline c) Chat or instant messaging (e.g. Texting, Snapchat) & 1 \\
\hline d) Downloading or uploading documents & 1 \\
\hline e) Downloading or uploading audio or video files & 2 \\
\hline f) Streaming audio / video (e.g. live sport / Spotify) & 1 \\
\hline g) Skype/FaceTime/Other VoIP & 1 \\
\hline h) Sending or receiving personal emails & 1 \\
\hline i) Using work services (e.g. work email / file sharing) & 2 \\
\hline j) Internet banking & 1 \\
\hline k) Paying for goods or services using Paypal & 1 \\
\hline l) $\quad$ Paying for goods or services using a credit card & 2 \\
\hline m) Something else (please specify) & 2 \\
\hline
\end{tabular}

Q16 Assuming a public wi-fi network was available to you, would you prefer to use public wi-fi or your 3G/4G mobile data for the activities listed? (Rotate order)

\begin{tabular}{|l|c|c|c|c}
\cline { 2 - 5 } \multicolumn{1}{c|}{} & $\begin{array}{c}\text { Public } \\
\text { wi-fi }\end{array}$ & $\begin{array}{c}\mathbf{3 G / 4 G} \\
\text { Mobile data }\end{array}$ & $\begin{array}{c}\text { No } \\
\text { preference }\end{array}$ & $\begin{array}{c}\text { Would not do } \\
\text { this activity }\end{array}$ \\
\hline a) General internet browsing & 1 & 2 & 3 & 4 \\
\hline b) Social networking (i.e. Facebook / Twitter/Instagram) & 1 & 2 & 3 & 4 \\
\hline c) Chat or instant messaging (e.g. Texting, Snapchat) & 1 & 2 & 3 & 4 \\
\hline d) Downloading or uploading documents & 1 & 2 & 3 & 4 \\
\hline
\end{tabular}

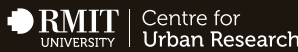




\begin{tabular}{|l|l|l|l|l}
\hline e) Downloading or uploading audio or video files & 1 & 2 & 3 & 4 \\
\hline f) Streaming audio / video (e.g. live sport / Spotify) & 1 & 2 & 3 & 4 \\
\hline g) Skype/FaceTime/Other VoIP & 1 & 2 & 3 & 4 \\
\hline h) Sending or receiving personal emails & 1 & 2 & 3 & 4 \\
\hline i) Using work services (e.g. work email / file sharing) & 1 & 2 & 3 & 4 \\
\hline j) Internet banking & 1 & 2 & 3 & 4 \\
\hline k) Paying for goods or services using Paypal & 1 & 2 & 3 & 4 \\
\hline I) Paying for goods or services using a credit card & 1 & 2 & 3 & 4 \\
\hline m) Something else (please specify) & 1 & 2 & 3 & 4 \\
\hline
\end{tabular}

\section{$\underline{\text { ASK ALL }}$}

Q17 How secure do you think public wi-fi networks are in terms of protecting your private information?

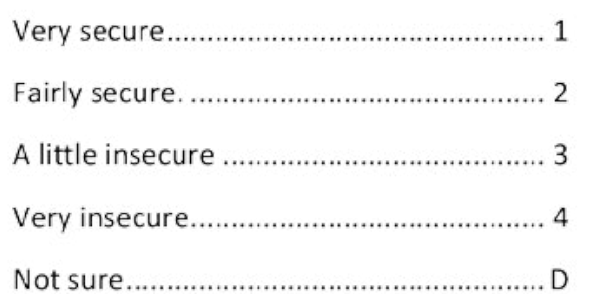

Not sure... D

\begin{tabular}{|c|c|c|}
\hline \multirow[t]{2}{*}{ Q18 } & $\begin{array}{l}\text { Thinking about protecting your private information on } \\
\text { public wi-fi networks, in your opinion, how important is it } \\
\text { to sign in with a password? }\end{array}$ & Very important ........................................ 1 \\
\hline & & Not important \\
\hline
\end{tabular}

Q19 As far as you are aware, which of the following will protect your private information when using a public wi-fi network? (Rotate order)

\begin{tabular}{|l|c|c|c}
\cline { 2 - 4 } \multicolumn{1}{c|}{} & Yes & No & Not sure \\
\hline a) Virtual Private Network (VPN) & 1 & 2 & D \\
\hline
\end{tabular}




\begin{tabular}{|c|c|c|c|c|}
\hline & Firewall & 1 & 2 & D \\
\hline d) & Anti virus & 1 & 2 & D \\
\hline e) & SSL & 1 & 2 & D \\
\hline & DNS Proxy & 1 & 2 & $D$ \\
\hline
\end{tabular}

\section{IF AWARE OF ANY IN Q19, DISPLAY THOSE OPTIONS AND ASK Q20}

Q20 Do you use any of the following tools or access methods to protect your private information when using public wi-fi?

\begin{tabular}{|c|c|c|c|c|}
\hline & Yes & No & Not sure \\
\hline g) & Virtual Private Network (VPN) & 1 & 2 & $D$ \\
\hline & HTTPS & 1 & 2 & D \\
\hline i) & Firewall & 1 & 2 & D \\
\hline j) & Anti virus & 1 & 2 & D \\
\hline k) & SSL & 1 & 2 & D \\
\hline l) & DNS Proxy & 1 & 2 & $\mathrm{D}$ \\
\hline
\end{tabular}

\section{ASK ALL}

Q21 Are you aware of any other tools or methods that might improve the security of using public wi-fi networks?

Yes (please specify) ................................... 1

Don't know .......................................... D

\section{$\rightarrow$ RMIT $\mid \begin{aligned} & \text { Centre for } \\ & \text { UNversir }\end{aligned}$ Urban Research}


Appendix 3: List of public wi-fi terms and conditions reviewed

\section{Australia}

Australia Post

http://auspost.com.au/media/documents/telstra-wifi-terms-conditions-oct2014.pdf

City of Darwin

http://www.darwin.nt.gov.au/node/2464

City of Kingston

http://www.kingston.vic.gov.au/library/Library-Services/Public-Internet-Gateway

City of Stirling

http://www.stirling.wa.gov.au/Pages/WiFi-Terms-and-Conditions.aspx

Colac Otway Shire

http://www.colacotway.vic.gov.au/System-pages/WIFl-terms-of-use

Craigieburn Central

http://www.craigieburncentral.com.au/legal/wifi-terms/

\section{Fair Work Commission}

https://www.fwc.gov.au/news-media/guest-wi-fi-service-terms-conditions

Internode

http://www.internode.on.net/pdf/legal/internode-hotspot-end-user-terms.pdf

\section{Macquarie Centre}

https://www.macquariecentre.com.au/MacquarieCentre/media/contents/05_Centre_ Information/MyMacquarie-Free-WiFi-T-C-s-FINAL.pdf

\section{McDonalds}

http://www.wirelesslans.com.au/wifi/mcdonalds-free-wifi/free-wifi-tacs.html
Melbourne Airport

http://melbourneairport.com.au/flight-passenger-info/aiport-facilities/wireless-internet-termsof-use.html

Moonee Valley Racing Club

https://thevalley.com.au/mvrc/policies/terms-conditions

National Gallery of Australia

http://www.nga.gov/content/ngaweb/visit/public-wifi.html

Penrith Panthers Rugby League Club

http://penrith.panthers.com.au/free-wifi/

Queensland Airports Ltd

http://www.townsvilleairport.com.au/wp-content/uploads/2010/11/QAL-Public-Wifi-End-UserTerms-and-Conditions.pdf

\section{Queensland Museum}

http://www.gm.qld.gov.au/Visit+Us/Facilities/Wireless+Internet/

Wireless+Internet+Public+Access+Terms+and+Conditions\#.WEzPiZN961s

Queensland Parks

http://queenslandnationalparks.com.au/information/wifi-hotspot-terms-and-conditions/

\section{Queensland Rail}

https://www.queenslandrail.com.au/Wi-Fi/Pages/Terms-and-conditions-of-use.aspx

Redland City Council

http://www.redland.qld.gov.au/RecreationFacilities/RedlandLibraries/Documents/ITC\%20

Terms\%20and\%20conditions.pdf

Robina Town Centre 
http://www.robinatowncentre.com.au/u/legal/wi-fi-terms-and-conditions.aspx

State Library of Victoria

http://www.slv.vic.gov.au/about-us/policies-guidelines/entry-service-policies/ict-use-andsecurity-policy

\section{Sunshine Coast Council}

https://www.sunshinecoast.qld.gov.au/Living-and-Community/New-Residents/Free-PublicWiFi/Free-Public-WiFi-Terms-and-Conditions

\section{Telstra Air}

https://www.telstra.com.au/content/dam/tcom/personal/consumer-advice/pdf/consumer/ telstra-air.pdf

\section{The Coffee Club}

http://www.coffeeclub.com.au/terms-and-conditions-for-using-the-coffee-club-free-wifi/

\section{Westfield Shopping Centres}

https://www.westfield.com.au/terms-and-conditions\#online-terms-conditions-of-use

Whitehorse Manningham Regional Library Corporation

http://test.emerg.com.au/WML/files/Plans_reports_policies/Public_Access_Technology_ Conditions_of_Use_2013.pdf

\section{International}

Bankers Life Fieldhouse (USA)

http://www.bankerslifefieldhouse.com/wifi-terms-of-use/

City of Calgary Library (Canada)

http://calgarylibrary.ca/public-access-network-terms-of-use/

City of Tempe (USA)

http://www.tempe.gov/city-hall/communication-and-media-relations/wifi-terms-of-service
City of Vienna (Austria) https://www.wien.gv.at/english/administration/ict/wlan/terms-ofuse.html

Feathers Royal Hotel (UK)

http://www.feathersroyal.co.uk/wifi-terms-conditions/

Ikea (International) IKEA

http://www.ikea.com/ms/en_US/privacy_policy/terms_conditions.html

Manchester City Council (UK)

http://www.manchester.gov.uk/downloads/download/6164/free_wifi_policies

\section{City of Middleborough (USA)}

http://www.middleborough.com/documents/

BOSVoted7152013MiddleboroughPublicWiFiAgreement.pdf

Panera Bread Bakery Café (USA)

https://www.panerabread.com/en-us/company-information/wifi-terms-of-use.html

\section{RMIT $\mid \begin{aligned} & \text { Centre for } \\ & \text { UNIVRSSTYY }\end{aligned}$}


DMIT | Centre for UNIVERSITY Urban Research

Centre for Urban Research

Building 15, Level 4

RMIT University City campus

124 La Trobe Street

Melbourne VIC, 3000

Australia

T: +61 399250917

E: cur@rmit.edu.au

\section{www.cur.org}

f facebook.com/RMITCUR

(v) @RMIT_CUR 